\title{
From genes to network models of Alzheimer's disease: Biological framework for multi-scale brain simulation with The Virtual Brain
}

\author{
Leon Stefanovski ${ }^{1 *}$, Jil Mona Meier ${ }^{1}$, Roopa Kalsank Pai ${ }^{1,2}$, Paul Triebkorn ${ }^{1,3}$, Tristram \\ Lett $^{1}$, Leon Martin', Konstantin Bülau', Martin Hofmann-Apitius ${ }^{4}$, Ana Solodkin ${ }^{5}$, \\ Anthony Randal McIntosh ${ }^{6}$, Petra Ritter ${ }^{1,2, *}$
}

${ }^{1}$ Charité - Universitätsmedizin Berlin, Corporate Member of Freie Universität Berlin, HumboldtUniversität zu Berlin, and Berlin Institute of Health, Department of Neurology, Brain Simulation Section, Berlin, Germany

${ }^{2}$ Bernstein Center for Computational Neuroscience Berlin, Berlin, Germany

${ }^{3}$ Institut de Neurosciences des Systèmes, Aix Marseille Université, Marseille, France

${ }^{4}$ Fraunhofer Institute for Algorithms and Scientific Computing SCAI, Sankt Augustin, Germany

${ }^{5}$ Behavioral and Brain Sciences, University of Texas at Dallas, Dallas, TX, United States

${ }^{6}$ Baycrest Health Sciences, Rotman Research Institute, Toronto, Ontario, Canada

* Correspondence:

Leon Stefanovski

leon.stefanovski@charite.de

Petra Ritter

petra.ritter@charite.de

Keywords: Alzheimer's Disease, The Virtual Brain, Brain Simulation, Multi-scale Brain Modeling, Connectomics

\begin{abstract}
While the knowledge in neuroscience and the possibilities in clinical neurology have improved for many years, neurogenerative diseases and associated dementia remain a growing problem. Alzheimer's Disease (AD) is the most common cause of dementia and also represents the most prevalent type of neurodegenerative diseases. For $\mathrm{AD}$, disease-modifying treatments are presently lacking and the understanding of disease mechanisms remain incomplete. In the present review, we consider candidate contributing factors leading to $\mathrm{AD}$ and we evaluate novel computational brain simulation methods to further disentangle their potential roles. We first discuss existing computational models of AD that aim to provide a mechanistic understanding of the disease. Next, we outline the potential to link molecular aspects of neurodegeneration in $\mathrm{AD}$ with large-scale brain network modeling using The Virtual Brain (TVB, www.thevirtualbrain.org), an open-source, multiscale, whole-brain simulation neuroinformatics platform. Finally, we discuss how this methodological approach may contribute to the understanding, improved diagnostics and treatment of $\mathrm{AD}$.
\end{abstract}




\section{REVIEW}

\section{Introduction}

Every second senior with an age above 90 years suffers from Alzheimer's disease (AD) or another dementia (1). The mortality rate in the US for people with this neurodegenerative disease (NDD) exceeds that of breast cancer and prostate cancer combined (2). Beyond the impact on individual life circumstances of patients and their families, NDD has an enormous economic impact and hence poses a massive societal burden. The Alzheimer's Association's latest report estimates the annual medical and care costs attributed to AD in the U.S. at \$290 billion in 2019 (2). By 2050, this number is expected to rise as high as $\$ 1.1$ trillion (3). It is estimated in the same report, that early diagnosis at the stage of mild cognitive impairment (MCI) could save up to $\$ 7.9$ trillion in cumulated medical and care costs by the year 2050. While the prevalence of AD, the most common type of NDD (1, 2 ), increases, the underlying disease mechanisms are still not understood. No disease modifying treatment does exist. Despite the collection of large data sets and major advances in high throughput computational methods, what is lacking are theoretical frameworks that link the many pieces observations to infer the underlying causes. The brain has multiple levels of organization (e.g., molecular, cellular, ensemble- and region-level) including both feedback and feedforward interactions between and within those different levels. These dependences are nonlinear, leading to emergent phenomena - features of the system that cannot be understood by the simple "sum" of its parts. Small perturbations in such nonlinear systems can have large unexpected consequences. In the brain, interactions traverse many spatial and temporal scales, thus focusing on one scale can underestimate the emergent phenomena at other scales.

A mechanistic understanding of AD opens new horizons for early diagnostics and cause-targeting treatments. Recent pharmacological clinical trials testing substances such as anti-Amyloid-beta (Abeta), tau-protein targeting (4) and immune-modulating substances used for rheumatoid arthritis, have experienced major setbacks. The development of novel therapeutics would clearly benefit from theoretical and computational approaches (5).

We hypothesize that the key to both understanding and curing AD lies in the characterization of the features and processes that control emergent phenomena in the brain. To reach this goal, a deep understanding of state-of-the-art biological research on AD and detailed knowledge of the tools offered by computational brain modeling are required. In this review, we summarize current findings of $\mathrm{AD}$ pathogenesis from genomics to connectomics - describing the contribution of the classic hallmark proteins as well as current research on the Notch-1 pathway, neurotransmitters, polygenetic factors, neuroinflammation and neuroplasticity. In the second part, we present various approaches of computational modeling of AD disease mechanisms and discuss their benefits and disadvantages. In the last part, we describe The Virtual Brain (TVB, www.thevirtualbrain.org) as a multi-scale brain simulation platform that enables linking molecular signaling cascades with largescale brain simulation. An overview about the structure of this article is given by the flowchart in Figure 1. 


\section{PART I: Alzheimer's Disease Research. Background}

\section{I.1: Historical considerations}

While nowadays dementia is a descriptive term for (acquired) severely impaired cognitive function due to a brain disease, dementia has historically been understood as a mainly physiological loss of mental function in the elderly (6). Psychiatrists have therefore contrasted the cognitive disorders of the young ('dementia praecox'), today classified e.g. as schizophrenia, against dementia in the old, 'dementia senilis' - i.e. the classification of dementia was dependent on the age at which the cognitive impairment occurred (7). A profound challenge to this concept was posed in 1907 by the observation of Alois Alzheimer when his patient, Auguste D., had a characteristic psychopathology of dementia rapidly progressing - at an early age of 56 years $(8,9)$. Based on his observations of an "unusual disease", a new field of neurologic and psychiatric research emerged. Various mechanisms, risk factors, etiologic components (i.e. underlying causes such as for example neurotoxic proteins, risk-modifying genes, etc.) and comprehensive classifications of cognitive disorders were developed. Interestingly much later in 2013 (10), it was shown that Auguste D. suffered from an early-onset variant of Alzheimer's dementia. A truly "unusual" and rare disease, which is one of the monogenetic forms with a mutation in the presenilin gene PSEN1 (10). Yet the primary cause of AD and also criteria for its diagnosis still remain unclear. Even the diseasedefining biochemical findings of the pathology in $\mathrm{AD}$, represented by amyloid beta $(\mathrm{A} \beta 40$ and $\mathrm{A} \beta 42$, in the following Abeta) and the phosphorylation of the $\tau$ protein (TAU for tubulin-associated unit or by the Greek letter $\tau$, in the following Tau; for a review, see (11)), remained controversial as causative of the disease trajectory and cognitive symptoms. Nevertheless, their presence during pathogenesis is undisputable (12-14).

\section{I.2: Definition and diagnostic criteria}

Nosology is the discipline of disease classification based on the underlying disease mechanisms. A disease classification in this sense can only be assigned if the underlying etiology of the respective disease has been established. Otherwise, we speak of a "syndrome" or "disorder" (15). The dementia syndrome encompasses a broad array of different possible etiologies of cerebral or systemic origin $(1,16)$. Clinically it presents as a set of signs and symptoms. The affected neurocognitive domains are the higher cortical functions, namely: Memory, language, attentional processing, executive functions and visuo-spatial domains. Different diagnostic criteria are being used for the diagnosis of AD.

Amongst the most used diagnostic criteria is the NINCDS-ADRDA (National Institute of Neurological and Communicative Disorders and Stroke and Alzheimer's Disease and Related Disorders Association) definition of 1984, where possible and probable AD are defined purely by clinical (e.g. daily life impairments) and neuropsychological criteria in the absence of further diagnostic evaluation with technical means (17). At the core of this definition is the presence and slow progression of cognitive decline in two or more cognitive domains including memory, as well as the absence of alternative causes of dementia. In the revision of these criteria in 2011, it was further specified that impairment in activities of daily living (ADLs) is necessary for the diagnosis of the dementia syndrome (18). 
In clinical practice, a diagnosis is mainly established based on the definition of probable AD according to NINCDS-ADRDA and through the exclusion of potential other causes of dementia (19). One challenge with this purely symptomatic definition of $\mathrm{AD}$ is posed by the various phenomenological forms of $\mathrm{AD}$ (16). Clinical symptoms and neurodegeneration occur on a continuum. They can vary tremendous across indviduals. The most common phenotype of AD is the slowly progressive amnestic variant. However, it is not uncommon that dysfunction of language, disorientation, apraxia or neuropsychiatric signs like affective symptoms appear first, while memory deficits seem not to be predominant. This heterogeneity in phenotypes can have various causes, such as educational and social factors, structural vulnerability of the brain or the individual cognitive "reserve" of each patient (20). The clinical definition of AD gets further complicated due to an overlap in symptoms with those of other dementias and comorbidities that can influence the clinical presentation. For example, if the patient suffers also from depression, possibly caused by the beginning cognitive decline, this mood disorder itself can impact memory. And if patients also suffer from Parkinson's disease - do they then necessarily have Parkinson's dementia? Or AD and Parkinson's at the same time? Or has the neurodegeneration caused by the Parkinson's disease diminished the cognitive reserve, which lead to the clinical onset of $\mathrm{AD}$ ?

In contrast to the original NINCDS-ADRDA classification, the current diagnostic definition from the NIA-AA (National Institute of Aging and Alzheimer's Association) in 2018 is based on the presence of Abeta and Tau proteins in cerebrospinal fluid (CSF) or positron emission tomography (PET) and atrophy signifying neurodegeneration in brain imaging. The NIA-AA definition introduces the AT(N) classification to standardize biomarker findings in AD: therein A stands for positive Abeta biomarkers, $\mathrm{T}$ for phospho-Tau biomarkers, and $\mathrm{N}$ for Neurodegeneration markers in cerebrospinal fluid (total Tau burden) or atrophy shown in magnetic resonance imaging (MRI). The cognitive dimension of the disease is handled separately (and can be added to the classification as the letter $\mathrm{C}$ in its extension ATNC). This definition is primarily intended for application in research and not used in clinical routine practice (15). It is debated whether this definition may prevent shifting scientific attention to other important candidate factors contributing to AD - which might lead to missing mechanistic cascades beyond Abeta and Tau proteins (21).

While the NINCDS-ADRDA definition only considers cognitive symptoms, the NIA-AA definition does not consider cognitive symptoms in the core AT(N) classification at all (15). Therefore, possible more specific classifications could be "Alzheimer's disease with dementia" or "Alzheimer's disease with mild cognitive impairment" instead of the currently used term "Alzheimer's dementia", which merges both, AD pathologic changes and dementia syndromes (15).

Despite clinical classifications for probable AD (17) or research frameworks as the definition of $\mathrm{AD}$ by dementia with $\mathrm{A}+\mathrm{T}+\mathrm{N}+$ biomarkers (15), only the exploration of invasively obtained tissue samples either in the living person through biopsy or post-mortem at autopsy can provide definitive diagnosis of $\mathrm{AD}$ - by proofing the presence of neuritic plaques (with Abeta) or neurofibrillary tangles (with Tau). Autopsy is the more likely course of action as highly invasive interventions that could secure a diagnosis in vivo are rarely performed because of the lack of causal diseasemodifying treatment options. The rate of confirmation of clinically diagnosed AD by autopsy was calculated in a meta-analysis with a sensitivity of $85.4 \%$ and specificity of $77.7 \%$ (22). However, even the neuropathological examination of brain tissue as the state-of-the-art gold standard method for $\mathrm{AD}$ diagnosis often reveals several protein-related pathologies, i.e. those represented by the typical picture for $\mathrm{AD}$ plus others that have been associated with other neurodegenerative diseases (23). 
Possible prodromal stages of dementia, e.g. mild cognitive impairment (MCI) and subjective cognitive decline (SCD), do not meet the clinical criteria for a dementia syndrome because the patients have no deficits in the ADLs. In MCI, cognitive deficits are measurable, but still do not affect ADLs (24). In SCD, it is not objectively possible to measure the deficits in neuropsychological examinations, but patients complain about cognitive deficits they notice (25). These states may in some cases be critical phase transitions of the disease trajectory to dementia. In combination with other factors, they may help assessing the risk of an individual to develop manifest dementia (26).

Diagnosis is often an important question for the patient and the patients' families - even in the absence of helpful therapeutic interventions because this provides more certainty regarding the prognosis of disease and the development of care plans. The consequence of not knowing the diagnosis for the individual patient, especially for the elderly with potential comorbidities, is that it is often not clear to what extent distinct types of dementia and related disorders actually contribute to the cognitive impairment $(27,28)$.

\section{I.3: Epidemiology}

Neurodegeneration is a continuum where several factors, such as proteinopathies, vascular and immunological changes likely interact (23). Within the spectrum of dementias, the most common dementia is $\mathrm{AD}$, followed by vascular dementia (VD) and mixed dementia that is a combination of $\mathrm{AD}$ and VD (29) (Figure 2, data from (1)). Frontotemporal dementias and Parkinsonian syndromes, in particular the Lewy-body dementia and the Parkinson dementia, occur with lower prevalence than AD. A systematic overview of the most common and clinically important dementias is presented in Figure 3. The diagnosis of dementia-underlying diseases is challenging. Dementias can occur due to primary NDDs, i.e. AD, mixed dementia, frontotemporal and Lewy-body dementia, and secondary dementias linked to vascular changes (VD), immunology, infections and other diseases (Figure 3). Yet this differentiation is a simplification, as many secondary dementias arise from neurodegenerative processes during the disease course of primarily non-neurodegerative diseases, . A well-known example is the neurodegenerative course in late stages of multiple sclerosis (30).

The relevance of correct diagnoses results from the different treatment strategies and prognoses as they relate to different types of dementia. Some of the possible causes of dementia are curable such as normal pressure hydrocephalus, metabolic disorders, and immunologic or infectious causes. While presently no disease-modifying therapy for any primary neurodegenerative disease exists (2), future therapies as well as ongoing symptomatic and more experimental studies may benefit from a careful patient stratification. This is in particular important for approaches that aim to model $\mathrm{AD}$ mechanisms with patient data, as the resulting model will only be as specific to $\mathrm{AD}$ as the patients were assigned to the correct (and strict) diagnosis. An overview about the experimental therapies that are in development for AD can be found in Table 1. For the established treatments for other dementia causes, see Table 2.

The population above 80 years is the group where the prevalence of dementia is increasing the most (31). While different pathogenic pathways have been hypothesized for $\mathrm{AD}$ and VD, it is 
increasingly acknowledged that both syndromes share many risk factors (32). However, interactions of Abeta in AD with vascular factors (e.g. altered blood-brain barrier permeability caused both by microvascular changes and Abeta deposition (33)) and can be differentiated from cerebral amyloid angiopathy (34), a distinct vascular disease caused by amyloid, which we will not discuss further here.

An increased rate of cerebrovascular disease manifestations and thus a higher incidence of VD correlates with lifestyle and atherogenic risk factors such as physical activity $(35,36)$, diabetes mellitus (37) and hypercholesterinemia $(38,39)$, which are also risk factors for AD $(32,40)$. However, mechanisms whereby these factors mediate their impact has been debated (41). One hypothesis is that microvascular lesions remain undiscovered leading to a failure to diagnose a vascular or mixed dementia. Another possibility is an involvement of metabolic pathways in the pathogenesis. Notably, the most important genetic risk factor in the whole population, APO-E $\varepsilon-4$ hetero- or monozygotic, is an allele of a metabolic gene, which also modulates the atherosclerotic risk $(42,43)$. Especially in the elderly, the prevalence of both etiologies, atherosclerosis and neurodegeneration, increase exponentially and could therefore likely affect the same individuals (44). Although the role of metabolic factors is not clear, epidemiological approaches have shown that up to one third of cases attributed to AD might be preventable by addressing these modifiable risk factors (45). However, this evidence comes from a mere observational method using the population-attributable risk. This statistical method describes the fraction of the incidence of a disease that can be attributed to one particular risk factor. While this index allows an estimation of the effect that might follow on the removal of the risk actor, as a result from an observational study it precludes establishing a clear causal relation between observed risk factors and the disease (46). For example, if the definition of $\mathrm{AD}$ in the underlying observational study is inconsistent and therefore contains also other disease entities as mixed dementia, the population-attributable risk would be related to mixed dementia as well as to AD itself. A reduction of atherosclerotic risk factors might therefore affect the mixed dementia patients instead of "pure" AD cases.

\section{PART II: Brain Alterations in Alzheimer's Disease: from Genes to Brain Networks}

\section{II.1: Genetics}

Early-onset $\mathrm{AD}$ can be a familial disease with rare structural variants or copy number variants in genes that regulate Abeta production and clearance. For example, structural variants in the Amyloid precursor protein $(A P P)$ gene affect post-translational processing of $A P P$ by secretases leading to excess Abeta in early-onset AD. The presenilin 1 (PSEN1) and presenilin 2 (PSEN2) genes form

the active component of the $\gamma$-secretase complex. It is critical for processing APP as well as other type-I integral membrane proteins, including members of the Notch signaling pathway and receptor tyrosine-protein kinase erbB-4 (ErbB4) (47). There are autosomal dominant mutations of PSEN1 and PSEN2 that affect endopeptidase and carboxypeptidase activity leading to longer and more toxic forms of Abeta peptides $(48,49)$. Other environmental and genetic factors may contribute to the etiology of early-onset $\mathrm{AD}(50)$.

In contrast, late-onset $\mathrm{AD}$ is a complex genetic disease in which rare structural variants and common variants, mostly identified by genome-wide association studies (GWAS), play an 
important role in etiology. The heritability of late-onset $\mathrm{AD}$ is estimated to be high with approximately $50 \%(51,52)$ - yet environmental factors are likely to be additionally important $(53$, 54). The single nucleotide polymorphism (SNP)-based heritability estimates are usually high in $\mathrm{AD}$, at approximately $25-30 \%$ (55), compared to other complex genetic brain disorders $(56,57)$. Apolipoprotein E $(A P O E) \varepsilon 2 / \varepsilon 4$ polymorphisms alone explain approximately $25 \%$ of the SNPbased heritability with common SNPs explaining the remaining $5-7 \%(52,55,58)$. The most recent three GWAS have identified 40 independent risk loci (58-60). The majority of these loci have functions in three main pathways: lipid metabolism, microglial activation, and APP processing (61). Importantly, many of these loci contain functionally relevant SNPs that impact expression in AD-associated cortical tissues and correlate with the expression of quantitative trait loci (eQTL) (58).

\section{II.2: Protein level}

Two most relevant proteins are associated with the pathogenesis of AD: Abeta and phosphorylated Tau. Abeta is a human protein which - due to an abnormally cleaved configuration - aggregates in neuritic plaques leading to its (neuro-)toxic effects (62-64). It can be found both intra- and extracellularly $(5,65,66)$. The hyperphosphorylation of the Tau protein has been suggested, develops as a consequence of the aggregation of Abeta (19). However, phosphorylated Tau is present in other neurodegenerative diseases not associated with Abeta deposition. Immunohistochemical analysis of brain tissue, which is more sensitive than standard microscopical tissue examination, reveals up to $92-100 \%$ of Tau in people who died with neurodegenerative disorders at a mean age of 71 years, in contrast to Abeta with $20-57 \%$ (67)). All subjects which fulfilled the official clinicopathological criteria for AD (ADNPC, defined as the presence of Abeta plaques, neurofibrillary tangles, and neuritic plaques (68)) in standard microcopy also showed Abeta and Tau by immunohistochemistry. But in the same group of ADPNC patients, two other protein pathologies could be measured; in $41-55 \%$ alpha-synuclein (associated to several diseases of the Parkinson spectrum) and in 33 - 40\% TAR-DNA-binding protein $43 \mathrm{kDa}$ (TDP-43, associated to amyotrophic lateral sclerosis and frontotemporal dementia; see also Figure 3). Therefore, 'pure' AD was a rare case in this cohort as $65-70 \%$ of confirmed AD patients suffered at least from one other neurodegenerative co-morbidity (67).

Neurodegeneration involving Tau has been characterized as primary and secondary tauopathies (69). A major argument in favor of the more prominent involvement of Abeta in driving the neurodegenerative process in $\mathrm{AD}$ is its higher specificity and its appearance in the early familial variants of $A D$, where the pathway is better understood $(19,62,63)$. In the past, most therapeutic strategies were aimed at Abeta (70-82).

\section{II.2.1: Amyloid Beta}

The deposition of Abeta typically follows a particular spatiotemporal pattern in the progression of AD. An illustration of this distribution can be seen in Figure 4. The course can be divided into three general stages (83-85): Stage A develops along the perirhinal and entorhinal cortices. Stage $\mathrm{B}$ involves the hippocampus proper and neighboring regions like the posterior gyrus parahippocampalis. Stage $C$ involves also a wide distribution of neocortical areas. Table 3 provides the list of brain regions that are specific to each amyloid stage. 
One possible explanation of the pathogenic deposition of Abeta is a maladaptive change in its processing, regulated by a group of secretases and other enzymes. We give only a short overview here. APP is a transmembrane protein whose function has been associated with neural development and synaptic plasticity (86). It can be processed to different subdomains. One possible way is the procession by the $\alpha$-secretase and subsequently the $\gamma$-secretase, which is called the nonamyloidogenic pathway (19). This "physiological" pathway does not lead to Abeta fragments (with $\beta$-helix), which can later aggregate to plaques, but APP gets transformed into a protein subdomain with $\alpha$-helix configuration (19). In another "pathological" pathway, by the $\beta$-secretase (and afterwards again the $\gamma$-secretase) APP is processed to soluble Abeta with $\beta$-helix configuration. The $\beta$-helices allow the molecules to aggregate together and build first Abeta oligomers and afterwards polymers, that become insoluble and deposit in the extracellular space, where they form the socalled beta amyloid plaques. The activation of this pathway leads to a decreased concentration of Abeta in CSF, because its insoluble configuration cannot be measured therein $(19,87)$. The imbalance between these two pathways, represented by the activity of $\alpha$ - and the $\beta$-secretase, is suggested to play a major role in the pathogenesis of AD and is currently, the target of various experimental treatment strategies (80, 82, 88-90) (Table 1 and Figure 5).

Another important feature, which is linked not only to the protein metabolism of Abeta, but also to neural development, is the Notch-1 pathway (91-93). Notch-1 is a membrane protein that plays a major role as the transcription factor for both, the NICD (Notch intracellular domain), and its extracellular domain NECD (94). The processing of Notch-1 to its subdomains is performed by the $\gamma$-secretase - the same secretase that is involved both in the amyloidogenic and non-amyloidogenic pathway of APP processing (94). APP and Notch-1 are co-substrates in the extracellular domain of the $\gamma$-secretase $(91,94)$. Notch-1 is found in Abeta plaques and its intracellular signaling is reduced in $\mathrm{AD}(94)$.

\section{II.2.2: Tau protein}

In the absence of any additional neuropathological factors in several dementias, phosphorylated Tau may play a major role in the degenerative process of primary tauopathies, including progressive supranuclear palsy (95), corticobasal degeneration and the spectrum of frontotemporal dementia (including Pick's disease) (69). In contrast, in secondary tauopathies, Tau seems to be involved in the pathogenesis only when other factors are present, as e.g. in prion diseases and chronic traumatic encephalopathy (69) (Figure 3). From this point of view, AD has a unique context because it is neither classified as a primary tauopathy (due to the concomitant presence of Abeta) nor is the amyloid pathology completely linked to Tau's hyperphosphorylation. However, the density of phosphorylated tau correlates better with the severity of cognitive decline than the accumulation of Abeta itself $(96,97)$. Hence, there is controversy on the role of the Tau protein in AD as either an independent disease factor or an indicator of general neurodegeneration derived from the neurotoxic effects of amyloid deposition. Clinical trials, based on anti-Tau-antibodies and vaccines, modulators of Tau aggregation and antisense oligonucleotides targeting its gene $M A P T$, are currently ongoing for AD patients $(98,99)$ (Table 1).

The pathology of Tau protein is complex and involved in several neurodegenerative processes (69, 95, 100). Different forms of neurodegeneration lead to a deposition of Tau (101), that can be measured in the cerebrospinal fluid (CSF) (102). In general, the phosphorylation homeostasis of the Tau protein is maintained by a series of kinases. A turn of this equilibrium towards a hyperphosphorylation of Tau protein shows two consequential effects: First, Tau loses its natural function of microtubule stabilization followed by a disturbed axonal transportation of vesicles, 
which leads consecutively to a disturbed axonal signal transmission. Second, the hyperphosphorylated Tau protein polymerizes to insoluble filaments and big tubular aggregates, the so-called neurofibrillary tangles (NFT). The brain's clearance system is unable to eliminate these aggregates leading to inflammatory processes and eventual neuronal death (19). These phenomena have been observed by using three methods: (i) microscopy of neuronal tissue with neurofibrillary tangles, (ii) observing an increased concentration of the hyperphosphorylated Tau section in the CSF, and (iii) non-invasive nuclear imaging methods that trace Tau protein $\left({ }^{18} \mathrm{~F}-\mathrm{AV}\right.$ 14-51 PET) (95). Because of its two main effects, namely neuronal death and axonal dysfunction, Tau leads to a disconnection of the affected regions in brain networks. This has been measured in regions with high binding of ${ }^{18} \mathrm{~F}-\mathrm{AV}-14-51$ PET tracing the Tau protein (95). The Tau protein is however a better marker in diagnostics for the severity of cognitive dysfunction than Abeta in AD (103). The local neurotoxic effects of Tau can be linked to network disruption as well as to an increased clinical score of apathy symptoms (104). The stages of Tau deposition (defined by post mortem histopathological criteria), similar to Abeta stages are called Braak and Braak Tau deposition stages $(83,84,105)$, show a characteristic spatio-temporal pattern formation in the course of typical AD (Figure 4). For this reason, most patients with a 'typical' AD show early tau depositions years before the onset of symptoms in the transentorhinal (perirhinal cortex, BA35) and entorhinal (BA28) cortices (stages I and II). This prodromal stage is followed by a further spreading into the limbic lobule (stages III and IV) and finally into the neocortex (stages V and VI) $(83,84$, 105). The phases of this dissemination process are separated in the six stages of tau deposition falling into three functional categories (i.e., transentorhinal/entorhinal, limbic, and neocortical), and have a good correlation to the cognitive decline of an individual AD patient $(96,97)$. Only the transentorhinal and entorhinal cortices are affected in the first stage of tau deposition, that is, the first functional category, where often only few amyloid plaques and no clinical symptoms can be observed. In detail, the non-obligatory prodromal stage of AD is characterized by an MCI, which often converts to the full clinical presentation of dementia and has, thus, a significant correlation to higher Braak Tau deposition stages $(96,97)$. In the limbic category, the findings are strongly associated with clinical symptoms of MCI stage (e.g. memory function, verbal fluency, impairments of daily life activities) (96). In the highest functional category, which concerns the neocortex, most patients have amnestic impairments (83-85). Similarly, the deposition of the Tau protein traced by ${ }^{18} \mathrm{~F}-\mathrm{AV}-1451$ PET correlates with the clinical presence of MCI as well as AD and also with cognitive performances (106).

The patterns of post mortem neuropathological and nuclear imaging findings are illustrated in Table 4. We can describe the six Tau deposition stages as follows: Transentorhinal category consists of stages I and II and concerns the transentorhinal cortex in the ventromedial temporal lobe, and later the entorhinal cortex in the lamina granularis externa (Lamina II). Limbic category consists of stages III and IV, and involves mainly the hippocampus and the temporal allocortex (Figure 4). The neocortical category consists of stage V and VI and concerns the spreading of Tau deposition to dorsolateral areas and primary functional areas of the whole neocortex. There seem to be a high correlation in general of the Tau deposition pattern and the pattern of amyloid deposition described above; however, it is worth mentioning that the three stages of amyloid deposition described by Braak and Braak, A, B, and C, do not strictly coincide with the tau deposition stages I to VI. The six stages of tau deposition follow a stricter distribution course and show some overlap with the amyloid deposition stages, in particular, within the ventromedial temporal allocortices and proisocortices and later temporoparietal neocortices (Tables 3 and $\mathbf{4}$ and Figure 4). The effects of both pathologies differ to a larger extend, for instance, in the specificity to $\mathrm{AD}$, to neurodegeneration in general, or to cognitive functions (107). However, the 'macro sequence' of archicortex mesiotemporal cortex - temporoparietal neocortex is the same as well as the impaired cognitive domains in $\mathrm{AD}$ (memory and visuoconstruction) are associated with those regions. 


\section{II.3: Neurotransmitters}

Of interest in the pathogenesis of $\mathrm{AD}$ are especially two transmitter systems: the cholinergic and the glutamatergic systems. Acetylcholine is one of the essential neurotransmitters in the brain. Its functions are pleiotropic: Acetylcholine is fundamental of the peripheral vegetative nervous system and of the neuro-muscular transmission. In the brain, acetylcholine is involved in many functional systems, but particularly expressed in the synaptic signaling of interneurons (108). The dysfunction of the cholinergic system is relevant in the pathogenesis of $\mathrm{AD}$, as acetylcholine is essential for memory consolidation (109). Anti-dementia drugs work as inhibitors of the acetylcholine esterase, increasing the concentration of Acetylcholine in the synaptic gap, and thus leading to a slightly improved memory function (109).

Considering the other relevant transmitter, that is, glutamate, the concept of excitotoxicity is essential. Excitotoxicity refers to calcium-mediated toxic effects due to a sudden increase in glutamatergic transmission. Anti-dementia drugs that are no inhibitors of the acetylcholine esterase - mainly the N-methyl-D-aspartate (NMDA) receptor antagonist memantine - decrease the glutamatergic transmission in the synaptic cleft. Glutamatergic dysfunction is also related to neuroinflammation and plasticity.

\section{II.4: Neuroimmunology}

Beside the cascades of Abeta and Tau, the second hallmark in AD pathogenesis is the role of neuroinflammation and autoimmunity. One of the difficulties in understanding the pathogenesis of $\mathrm{AD}$ is that intrinsic proteinopathic dysfunction alone does not necessarily lead to neurodegeneration and cognitive decline in the sense of losing brain function. Such impairments are more likely to be caused by various toxic intermediate mechanisms as discussed before. One potentially important but poorly understood mechanism is neuroinflammation. Neuroinflammation is a relevant factor in the pathogenesis of dementia, because it is in each case the last part of the pathogenic cascade and leads directly to neuronal death (110). However, it is not clear how the modulation of inflammation can affect the process of neurodegeneration. Clinical trials have shown contradictory results. For instance, the long-term administration of nonsteroidal anti-inflammatory drugs (NSAIDs) showed positive preventive effects and can hence reduce the a priori risk for $\mathrm{AD}$ (111). However, in contrast to those observational studies, prospective trials with steroids and other immunosuppressive drugs have shown no significant effects, as have randomized controlled studies with NSAIDs (112). A case-control study in patients with rheumatoid arthritis (who have a slightly higher risk for AD) showed significant reduction of $A D$ incidence by $70 \%$ (adjusted OR of $0.30, p=0.02$ ) if the patients were treated with the tumor necrosis factor $\alpha$ inhibitor etanercept (113), while it was well tolerable (114). As the etiology and differential diagnosis of dementia is often unclear, the label of AD could cover up a relevant percentage of autoimmunological neural phenomena that could be actually treated with high-dose and long-time corticosteroid therapies (115). The immunology of the brain is very complex, as it involves e.g. the organ-specific immunological cell type of microglia. An appropriate discussion would go beyond the scope of this review and we would like to refer the interested reader to the following review on neuroimmunology and AD (116). 


\section{II.5: Imaging}

\section{II.5.1: Anatomical MRI}

MRI offers a commonly used technique to screen for some of the before-mentioned biomarkers in vivo. As mentioned, the pathogenetic pattern of $\mathrm{AD}$ consists of the accumulation of amyloid plaques and NFTs. Volumetric assessment of grey matter loss in MRI has been identified to correlate with the distribution and degree of neurofibrillary tangles accumulation (117, 118). Therefore, volumetric MRI can provide a proxy measurement for regional NFT load (119).

The atrophy of memory-related structures has been consistently reported for AD patients, including the hippocampus and other mesiotemporal regions as well as the precuneus, cingulate and prefrontal areas (120-124). However, non-amnestic symptoms like e.g. aphasia, visuospatial problems or behavior predominant dysfunction are initially present in up to $30 \%$ of AD patients $(125,126)$. The distribution of NFTs in those patients with atypical clinical presentation is either limbic-predominant, hippocampal-sparing or not reported, which is also referred to as the noatrophy or minimal-atrophy AD variant $(119,127)$. A correlation between those phenomenological subtypes of $\mathrm{AD}$ and volumetric MRI has already been demonstrated (128) and multiple studies explored MRI as an in vivo marker of these AD subtypes $(119,129-131)$. Besides the atrophy patterns of syndrome variants in AD morphology, a few of single-region-based volume reductions have also been identified as potential biomarkers for AD. A detailed overview of these features is provided in Table 5 .

As a non-invasive in vivo measurement, MRI opens up the possibility of longitudinal tracking of atrophy and disease progression of AD. Recent studies investigated volume loss in AD patients longitudinally (132-134). Regions with reduced baseline grey matter volume also have a trend to show more atrophy over time and the highest atrophy rates in the temporoparietal regions (134).

Besides grey matter atrophy, white matter hyperintensities, which appear on T2-weighted or fluid attenuated inversion recovery (FLAIR) MRI scans, have a high prevalence among AD patients (135). White matter hyperintensities in general can be morphological correlates of microvascular lesions as well as inflammatory or unspecific changes in aging. An increase of the volume of these hyperintensities has already been observed in PSEN1, PSEN2 and APP mutation careers approximately six to 22 years before estimated symptom onset of AD (136). The relationship between white matter hyperintensities and AD pathology is still an active research field (137).

\section{II.5.2: Positron Emission Tomography}

Nuclear imaging methods allow in vivo acquisition of metabolic features of the brain by the usage of various radioactively marked tracer molecules, so-called radionuclides. In neuroscience, in particular PET offers the possibility of different functional assessments of the brain. The underlying physics make use of $\beta^{+}$-emitters - the emitted positrons of $\beta$-decay react with electrons of the tissue in a so-called annihilation, which leads to the emission of photons. The photons can be measured by specific sensors (138). 
Both Abeta and Tau deposits can be measured indirectly by PET and correspond well to the underlying pathologic changes at autopsy $(139,140)$. Tau tracer binding in AD is higher in regions that are known to be affected in early Braak stages $(104,106,132,139,141)$, as well as globally in the cortex $(106,133)$. However, Tau binding is also increased in healthy controls, predominantly located in areas with atrophic changes (132). Similarly, Abeta tracers show increased global deposition in the brain $(140,142)$ and in early Braak stage regions (143) (144). Although the partition of "Abeta-positive" healthy controls seems to be higher than for Tau (145-147).

Another important PET measurement is the assessment of energy metabolism by the usage of marked glucose molecules. Multiple studies suggest temporoparietal hypometabolism in AD (148152), which is already established in unclear cases for the differential diagnosis to other dementias in clinical practice. Interestingly, as atrophy patterns $(117,118)$, hypometabolism has a strong association to Tau deposits (153). The usage of glucose PET in clinical routine is limited by high costs, exposure to ionizing radiation and low sensitivity in the detection of MCI patients that will convert to $\mathrm{AD}(154)$.

An overview of PET findings in AD is provided in Table 5.

\section{II.5.3: Connectomics}

After discussing the recent advances researching the microscopic molecular level in AD, a wholebrain perspective can be considered at the macroscopic level of brain regions. Connectomic research is also an important aspect in understanding the development of cognition and its decline in dementia. There are various hypotheses highlighting aspects of the degeneration and, in general, network changes in dementia (155). One global idea refers to the hypothesis of disconnection syndromes (156). It states that in dementia very generally all anatomical connections (the structural connectivity $S C$, e.g. measured with diffusion-weighted MRI) are weakened, while in particular specific regions and their sub-networks disconnect, with a focus on the default mode network $(\mathrm{DMN})$, a large-scale network of regions strongly interconnected in resting state) (157-163). Although this is a phenomenon we can also observe in aging (164), the degree of DMN disruption allows in parts the distinction between healthy aging and AD (165).

The connectomic approach is a neuroscientific discipline that analyzes, describes and uses (axonal) connectivity measures of the brain (166). It provides an overview of the disease effects in AD and identifies global phenomena beyond the impairment of single regions. In the general framework of brain networks, brain regions are represented by nodes and connections between them (either structural or functional) are denoted as links or edges (Figure 6 shows an abstract example network). At this level of abstraction, it is possible to calculate graph-theoretic measures for the connectome, the network metrics (167). There exists a plethora of different - partly interdependent - metrics of which many are showing changes in AD networks compared to healthy controls. An overview of these findings is provided in Table 5. Heterogenous findings for different measurement modalities exist, which point towards a widely spanned network disruption in AD on different scales $(168,169)$. This heterogeneity can also be explained by different methodological choices for network construction, e.g. setting different thresholds for filtering out the most important connections (170-172). In general, however, converging evidence suggests aberrant functional connectivity (FC, measured by functional MRI) and white matter SC in AD compared to healthy aging. We review and align the recent literature on this topic showing multiple local network changes in $\mathrm{AD}$ resulting in the global phenomena of less efficient network communication for $\mathrm{AD}$ patients compared to healthy controls. 
$\mathrm{AD}$ has been viewed as a disconnection syndrome, where the loss of neurons and small-scale connectivity influences the macro-scale in the form of (structurally and functionally) disconnected brain areas $(169,173)$. This disconnection correlated with cognitive and behavioral decline (169) and white matter pathology in certain areas could be used as a biomarker for disease progression (174). This view on $\mathrm{AD}$ as a disconnection syndrome was able to bridge multiple scales of disease pathology in a coherent way. In recent years, however, network science studies on AD patients expanded this picture: widespread increases and decreases of connectivity within the brain network were observed, pointing towards compensatory mechanisms or reactions of the network beyond disconnection (169). Even an early but seminal study conveying the importance of "small networks studies" specially related to the initial disease stages showed isolation of the hippocampus from its cortical network connections via initial entorhinal cortex degeneration via the perforant pathway (175).

In network science, brain regions with high connectivity to other regions are called hubs. For both structural as well as functional connectivity studies, hub regions have consistently been shown as the most affected areas by AD (176-178). De Brier et al. show that even in preclinical stages of AD hubs are disrupted - in the form of two centrality measurements, the highest betweenness centrality nodes and high participation coefficient nodes (179). This vulnerability of hubs correlates with higher Abeta burden in these hub regions (160). For the functional network, especially the DMN is targeted by the AD-caused neurodegeneration (157-159, 161-163), where the highest Abeta deposition is also located. The extent of hub disruption correlates significantly with the cognitive status of a patient (162). Thus, it can be hypothesized that hubs - with their high Abeta deposition and central role in the overall information flow of the brain network - facilitate the spreading of the pathological cascade within the brains of AD patients (180). Aberrant or decreased $\mathrm{FC}$ has also been observed in the insula (181), posteromedial cortex (182), medial temporal cortex (183), and amygdala $(184,185)$.

Next to the vulnerability of hubs, a decreased global clustering coefficient has been reported showing a loss of connectedness and important redundancy structures for brain communication in FC, which consequently also alters the modular structure of AD patients $(161,179,186,187)$. Probably as a global effect of these "local attacks" on the network (Figure 6), decreased global efficiency in SC as well as FC networks is often observed in AD patients, which correlates with cognitive and behavioral decline $(161,188,189)$. Global efficiency is in network science defined as the inverse of the characteristic path length - with shorter pathways between the nodes, the information flow within the network is more efficient. A less efficient network can still provide connections between nodes, but they are longer and with more nodes and edges in-between (190).

Recent work analyzed a multimodal perspective on AD, combining diffusion tensor imaging (DTI), functional MRI and magnetoencephalography (MEG) measurements in a multilayer network (191). They found that for the combination of different modalities, the core of the network, which is likely to contain the hubs, has been most affected, which confirms the vulnerability of hubs across modalities. Together, these changes were able to predict the cognitive and memory impairment of patients (191). 
Emerging evidence suggest that in the pre-clinical stage of $\mathrm{AD}$, network changes are present in the form of a disconnection on a large scale (179, 192, 193). Indeed, FC and SC are now being investigated to better differentiate $\mathrm{AD}$ patients, $\mathrm{MCI}$, and controls moving towards the goal of identifying prodromal AD patients and the possibility of developing early intervention strategies $(187,194-196)$. A recent study suggests altered FC corresponding to accelerated aging in preclinical AD (197).

To sum up, both altered global and local connectivity have been associated with AD. Converging evidence from white matter diffusion tensor imaging and resting-state fMRI studies point towards less efficient network communication in AD patients compared to healthy aging, especially in the DMN.

\section{PART III: Modeling of Alzheimer's Disease}

Mathematical modeling is an adaptive and creative scientific concept and a core technique of computational neuroscience. As AD is a complex disease that takes place on various scales, a wide range of models have been developed for its research: e.g. animal disease models $(198,199)$, cognitive models (200) or disease progression / classification models (201-205). In general, one can differentiate between approaches focusing on single aspects of the disease, e.g. biochemical Abeta modeling (206), and integrative models incorporating several biomarkers while using multiple scales (205). The latter might be able to provide a more comprehensive, multi-modal view on the disease with its interacting mechanisms and might be therefore more suitable to reflect disease pathogenesis. This approach - also called "integrative disease modeling" (207) - combines functional and structural neuroimaging techniques, CSF sampling and/or genomic data and analyzes them and their intercorrelations using computational algorithms (202).

A comprehensive understanding of both the underlying biological processes of AD and the computational framework of high-performance modeling approaches is necessary to develop novel models for $\mathrm{AD}$ that integrate multiple scales, modalities, and research disciplines. With increasing technical possibilities for supercomputing and growing hierarchically organized knowledge architectures, this cross-disciplinary approach holds the potential to overcome some of the enigmas in AD pathogenesis that might not be revealed on a single scale with a single method.

Therefore, in the following sections, we will describe existing computational (brain) models of different scales and outline in how far they can be linked to the biological concepts presented before.

\section{III.1: Statistical disease prediction models}

Although statistical models are mainly of descriptive character, their criteria can also be of interest in the understanding of underlying disease mechanisms - beside their practical translational usage as diagnostic tools. A further discrimination of statistical AD models can be made between rather simplistic linear models (208) and more elaborate ones using advanced methods, such as machine learning tools. Both exhibit individual challenges and advantages regarding data analysis and model interpretation. Moreover, with regards to the more complex machine learning (ML) approaches, two major fields of use are present in the literature: prediction of disease trajectories (predictive 
modeling) and classification of subjects into groups with highly similar data points (discriminative modeling). The latter can be reached by (supervised) a priori labelling of the training data (e.g. as two classes $\mathrm{AD}$ and non- $\mathrm{AD}$, or as three-class problem with $\mathrm{AD}, \mathrm{MCI}$ or $\mathrm{HC}$ ). Clustering is possible without labelling, solely relying on statistical proximity measures (unsupervised discriminative models, (202)).

Structural T1-weighted MRI in conjunction with other biomarkers have been considered as features with classic ML techniques, e.g. support vector machines - often combined with other machine learning methods, such as linear discrimination analysis. Pellegrini et al. (209) reported that among 111 studies included in their review, AD was only successfully differentiated from healthy controls (HC) with satisfactory accuracy. The performance of classifiers differentiating MCI from healthy controls or AD, as well as the risk prediction of a conversion from MCI to AD was lacking (209). Thus, the clinical relevance of those classifiers remains rather low, given that - in practice - it is already possible to distinguish between $\mathrm{HC}$ and $\mathrm{AD}$ on the basis of cognitive performance. $\mathrm{A}$ diagnosis before clinically-noticed $\mathrm{AD}$ onset is therefore still missing.

An improvement could be achieved here by aiming at a deeper mechanistic understanding of AD beside its diagnosis. The relation of such a 'mechanistic biomarker', which is associated to the disease inside a complex knowledge system, is different from the purely associative character of a biomarker that is only related to the disease by correlation. In order to achieve a more accurate risk prediction of a transition from asymptomatic stages or MCI conditions into AD, biological mechanisms of this conversion have been computationally reconstructed. This was done with a predictive time-to-event model incorporating multimodal data ranging from genetic variants to neuroimaging and neuro-psychological assessments. Using a Bayesian Network model together with a literature-based validation, several biological risk factors and their interaction could be extracted (205). As the model makes use of a graph-like organization, it opens new horizons for the integration of multi-scale and multi-modal information and holds the potential to obtain information from biological knowledge bases like e.g. NeuroMMSig (https://neurommsig.scai.fraunhofer.de, (210)). In the hierarchical form of an ontology, it integrates chemical compounds, genes, proteins, medical terms and imaging features into a network of knowledge. This allowed to identify 125 subnetworks of pathways that are related to AD (210).

When adding longitudinal patient data to the models, further information about disease progression can be extracted and used to increase accuracy for subsequent predictions. For example, a combination of MRI measures of cortical thickness and clinical assessment scores (MMSE and ADAS-13) at two timepoints together with genetic information (ApoE $\varepsilon 4$ status) can be used to predict symptom trajectories in patients with different cognitive performance levels at baseline. Comparing different algorithms trained on multimodal data from two timepoints, a longitudinal Siamese neural-network showed highest performance, even after validation with another data set (203).

This longitudinal and multi-modal approach of predicting the individual risk and disease trajectories could thus represent promising new paths in personalized medicine. Modelling structural and metabolic changes in different areas of the brain in relation to the decline in cognitive functions can yield more sophisticated information about disease progression and its influencing factors on individual level (201). Future approaches could also incorporate a wider range of data modalities, such as is provided by the graph theoretically organized database EBRAINS of the Human Brain Project (https://ebrains.eu, (211)). 


\section{III.2: Sub-cellular models}

Brain simulation can take place on many different scales, as the complex topological hierarchy of the brain consist of many essential components: cortical and subcortical regions, networks, columns, ensembles, circuits, neurons, synapses, vesicles, molecules and genes (compare Figure 5).

Sub-cellular features of AD provide promising surrogates for computational modeling based on protein interaction and gene expression. AD mechanisms have therefore been modeled focusing on different aspects such as the deposition process of Abeta $(89,212-214)$. Biochemical models account for interaction between numerous of the interacting factors like Abeta, Tau, inflammation, different proteases and probable interventions (215-219) and are therefore quite complex.

Early studies have used computational modeling to assess the kinetics of aggregation for synthetic Abeta-like peptides (220). Comparably simple biochemical models allowed a mathematical description of the aggregation process - as the temporal evolution of Abeta in form of monomers, micelles and fibrils (221). Subsequently, the theory of Abeta aggregation could be enhanced by including more detailed interactions between different forms of Abeta fibrils and by fitting the model to empirical data (222). While the experimental findings on Abeta's toxicity increased, a particular model was developed that describes disrupted $\mathrm{Ca}^{2+}$ homeostasis and Abeta aggregation as a positive feedback loop that describes how both processes are interacting in a vicious circle (223). In the last decade, more specific models have included connections of AD to important gene transcription factors as p53 (224), possible intervention strategies (225) and genetic risk factors (217).

Concepts of sub-cellular modeling are valuable for the integration to multi-scale models as they describe the molecular hallmarks of AD in a computationally accessible manner. By means of computational linguistics and semantic frameworks, molecular pathways can be "coded" as a network of relations. One possible tool for this approach is the Biological Expression Language (BEL), which enables to describe the interaction between proteins, genes and other chemical compounds with means of first-order logics (226).

\section{III.3. Single-neuron and neural-circuit models}

Beside the subcellular scope, models of AD span over different microscopic scales, ranging from single cell models (227-230) to neural networks (227, 231-233).

Single-neuron models are often inspired by an experimental approach, such as a patch-clamp experiment (234), to reproduce the observed data (228). Underlying mathematics for those singlecell simulations may refer to general formulations for neural oscillation models, as it is the case for Hindmarsh-Rose neurons (235). This early model uses three coupled differential equations to simulate basic neural behaviors as oscillatory bursts (235).

To integrate more complex systems of more than just a few neurons, the mean-field theory can be used (236). The simplification of the mean-field has its origin in physics to describe the behavior of fluid or gas without taking into account individual molecules - in the brain, it allows to simplify the behavior of a spatially distinct group of neurons with a similar function (237). This group of neurons is called a neural mass and can be defined on various scales - e.g. as a brain region, a column or an ensemble. Neural mass models $(235,238-243)$ have been widely used to define local dynamics in a large-scale brain network model. 


\section{III.4: Large-scale brain network models}

The evolution of large-scale computational brain modeling considering the whole brain has been developed over the past decade. De Haan and colleagues (244) have built a model to test the hypothesis that excessive neural activity leads to neurodegeneration. This model is a large-scale brain network derived from diffusion MRI, where each network node holds a neural mass model by Zetterberg et al. (241) as its local dynamic model. De Haan and colleagues simplified the synaptic strength as a function of neural activity over time (244). As a result, those connections that were more frequented became weakened after a certain period of time. The purpose for the implementation of this specific mechanism was to describe a form of excitotoxicity that leads to degeneration. Here, after a certain period of time, one could consecutively observe degeneration in the functional and structural network topology using graph theoretical measures. The authors also observed a loss of spectral power and an increased sensitivity of hubs, defined by highly connected brain regions (incoming and outgoing ties) (244). The authors observed in the model an increase of brain activity and an increase of FC, similar to empirical findings in MCI or mild AD stages (244). In a subsequent study de Haan et al. (245) tested different "therapeutic" strategies like increasing or decreasing excitability of excitatory and inhibitory subpopulations of the neural masses to prevent neurodegeneration in the excitotoxic model. The most convincing strategy, which could maintain healthy network features over a long period of time, was an increased excitability of excitatory neurons that was followed by increased inhibition of inhibitory neurons. At a first glance, this might seem contradictory but it suggests the reversal of hyperexcitability by more excitation or less inhibition, respectively. The authors could however not provide a clear explanation for this effect but speculated that the reason lies in the network topology. The best strategies suppress the network hubs, which in return may lead to decreased disease propagation. According to this prediction, neurodegeneration spreads along the network infrastructure as a kind of "prodegenerative' signaling pattern.

Pons and colleagues used another brain network model for AD (246). This model uses at each cortical network node the neural mass model by Jansen and Rit (247), which is related to the Zetterberg model (241). The authors used EEG recordings that showed a slowing down of the alpha rhythm as well as an increase in FC (using phase lag index) in MCI patients with age, i.e. the FC increased from young to old subjects. Pons et al. were able to describe these observations by decreasing the maximum postsynaptic potential and increasing the thalamo-cortical SCs during the simulations.

In another modeling study, Demirtaş and colleagues have investigated the changes in BOLD signal due to $\mathrm{AD}$ in their recent modeling study (248). This study included 109 subjects from different groups (healthy controls, preclinical AD, MCI and AD). In empirical BOLD, one could observe a decrease in global interactions evaluating the first-order circular statistics, that is, Kuramoto order parameter, between healthy controls and $\mathrm{AD}$ as well as regional differences in the FC strengths. At the same time, FC strength differences were correlated to CSF biomarkers like Abeta, total Tau and phospho-Tau (248). Estimating an individual effective connectivity (EC) from subject-specific SC and $\mathrm{FC}$ with a heuristic approach, the brain model was able to replicate those changes in the network interactions. Local dynamics were described by a supercritical Andronov-Hopf bifurcation. In an in silico experiment using brain network models based on healthy subject's EC, they varied the order parameter of the model systematically (248). In this way, they were able to observe the progress of FC degeneration. An optimal order parameter was individually found for each disease stage / group, replicating best the empirical observed degeneration. This study showed how changes in the dynamics at each brain area can lead to disintegration of activity within the anatomical largescale brain network. At the same time, simulations also replicated the finding that the interaction 
(measured by Kuramoto order parameter) between BOLD signals declines with disease progression.

\section{III.5. The Virtual Brain platform}

In the following, we will focus on TVB, a multimodal and multiscale virtual brain simulation framework $(238,249-252)$ that holds the potential to combine different modeling scales for AD research. The open source platform of TVB is available under www.thevirtualbrain.org. TVB is a standardized and established framework that enables large-scale modeling approaches (as mentioned in the last section) on individual patient data and with a wide range of underlying dynamics.

TVB uses the structural connectome as its underlying basis (238). Most of the neural mass models (representing the region activity) implemented in TVB started as a network model for smaller, distinct networks - initially well-known entities like the motor network, the visual system or the Papez circuit, but with the development of connectomics, the networks included were more complex and elaborate (253). Likewise, the local dynamic models used in TVB were in principle composed for smaller or even single neuron systems $(235,238-243)$. Eventhough TVB was designed to simulate whole brain network dynamics, it can also model and simulate separate subnetworks ranging from regional level down to a few neurons (see (254) for hierarchy of integration in TVB).

The second important feature of TVB that can assist in the future of AD research is the multi-scale character. This term has been coined to describe the fluid transition of brain scales, ranging from the macroscale, at which brain regions interact intra- and inter-hemispherically via long-range connections, to the microscale of myriads of single neurons, where we have knowledge, on their electrophysiological properties, receptors, transmitters, position and wiring in cortical layers etc. In vivo measurement techniques at the macroscale offer information about individual brains, whereas measurements at the micro-scale are more specific to cell membrane and structure but cannot sample an entire individual brain. The concept of TVB addresses both scales: on the one hand, the $\mathrm{SC}$ of the whole brain is the scaffold of TVB and, on the other hand, the characteristics on the neural level are represented in the local dynamic models and its biophysiological parameters (e.g. the Jansen-Rit model). Modeling the large-scale brain may not comprise microscopical elements, but modeling the entire brain based on each single neuron may be computationally infeasible. For this reason, the mesoscale has been established $(255,256)$ and comprises different components: First, neural masses, which can cover the anatomical extent of a functional region or cover the neural mass in a voxel sampled by an MRI scanner. Depending on the neural mass model, they can refer to excitatory and inhibitory populations interacting with each other and through the largescale network, that is, the connectome, with distant regions. The interplay of this local circuitry in the large-scale brain network can produce physiologically plausible brain activity at a large scale (238, 249, 257-262). Second, another feature of the mesoscale is the spatial influence on neighboring regions through the evolvement of the electromagnetic field of the neural tissue and the temporal aspect of delay in the transmission along the white matter fiber tracts.

The prospect of TVB as an interdisciplinary research framework is that clinical applications and ensuing technologies may benefit and build on theoretical and computational predictions, as it has already shown success in epileptic surgery (263). TVB has already been used in a wide range of 
research topics, from the modeling of physiological brain phenomena in healthy participants (249, $251,254,264)$, mouse brain models $(265)$, to clinical approaches of AD $(266,267)$, epilepsy $(263$, 268), stroke $(269,270)$ and brain tumors $(271)$.

A recent study of Zimmermann et al. modeled AD using TVB (267). By fitting the model to predict individual FC from the underlying SC, the authors could show significant correlation between cognitive state of AD patients and the fitted model parameters of TVB (267). As the parameters are surrogates of biophysically relevant entitites such as long-range coupling factors and local interactions between inhibitory and excitatory neuronal populations, this enables the non-invasive estimation of intrinsic brain features.

For the field of AD, multi-modal data could include e.g. structural MRI, the SC out of DTI, and PET imaging data of Glucose metabolism, Amyloid and Tau. Our previous study (266) used one of these features, namely Abeta PET, to explore the mechanisms behind another prominent phenomenon in AD: the slowing in EEG (266). As a pilot study in this field, we modeled local Abeta-mediated hyperexcitability using brain network modeling where regional Abeta burden was derived from PET data. By defining the local Excitation-Inhibition balance as a function of local Abeta burden from PET, fundamental differences between the AD patients and controls were established in the absence of other differing factors the the Abeta distribution. We showed that few regions with moderate or high Abeta burdens are transferred into an altered dynamic state, wherein their activity oscillates slower. These slowing mainly presented as a shift from alpha to theta rhythms and was propagated throughout the network and focused to the hubs. Interestingly, local hyperexcitation as well took place in the central parts of the network. Therefore, with this approach, we were able to reveal a possible pathomechanism behind electroencephalographic slowing in AD (266).

\section{Conclusions and future directions}

Although our knowledge about the contributing factors in the pathogenesis of AD is increasing, it is still a major challenge in neuroscience to understand their distinct meaning and interaction. Moreover, the translation of these combined novel findings to clinical research is lagging behind. Rather than exploring isolated mechanisms, a goal is to integrate multi-modal datasets to reveal complex interactions underlying AD $(272,273)$ (Figure 7).

The main reasons for the development of precise and early diagnosis tools for dementia can be summarized as follows:

1. Future treatments. If a disease-modifying treatment for degenerative dementia would be available, it is very probable that it has to be performed many years before the clinical and behavioral manifestation of the disease. This is because we know that pathway changes in the brain begin decades before the onset of dementia and lead to irreversible cellular death of neurons. However, one has to expect of such a treatment that it will have to be taken for many years and might have severe adverse reactions - therefore not only a high sensitivity for the screening, but also a high specificity of the diagnosis will be of highest importance. Moreover, future trends of personalized treatments can only be outperformed with personalized biomarker-profiled patient 'fingerprints'. For example, a recent analysis has shown that the multimodal dataset from the Alzheimer's Disease Neuroimaging Database (ADNI) can predict the genetic expression pattern (as a potential individualized treatment target) better than the clinical presentation does (274) 
2. Differential diagnosis. A more precise diagnosis of AD will lead to the possibility to clarify those cases that seem to be atypical. Some etiologies could be identified with prospective treatments. Moreover, in the future, subtypes of disease entities could be identified, which are currently subsumed under $\mathrm{AD}$, and which could possibly get assessed by a specific treatment, e.g. autoimmunity phenomena with immunosuppression or early-onset $\mathrm{AD}$ with anti-Abeta drugs.

3. Study diagnosis. It is necessary to identify the right population to test new treatments. If the diagnosis is not clear enough, possible effects could be overlaid because of too many patients with other disease causes, in which the treatment does not show an effect. In the end, an approach of individualized medicine should be the goal.

4. Study monitoring. Because the clinical trajectories of the disease are slow and not easy to measure objectively, it is useful to use biomarkers for the monitoring of drug effects in study settings.

Using computational models for multi-scale brain simulations in future research may lead to improved diagnostics in early stages of dementia, to a more precise prognostic prediction and differential diagnosis as the fundamentals of rational medical treatment of AD patients. 


\section{FIGURES}

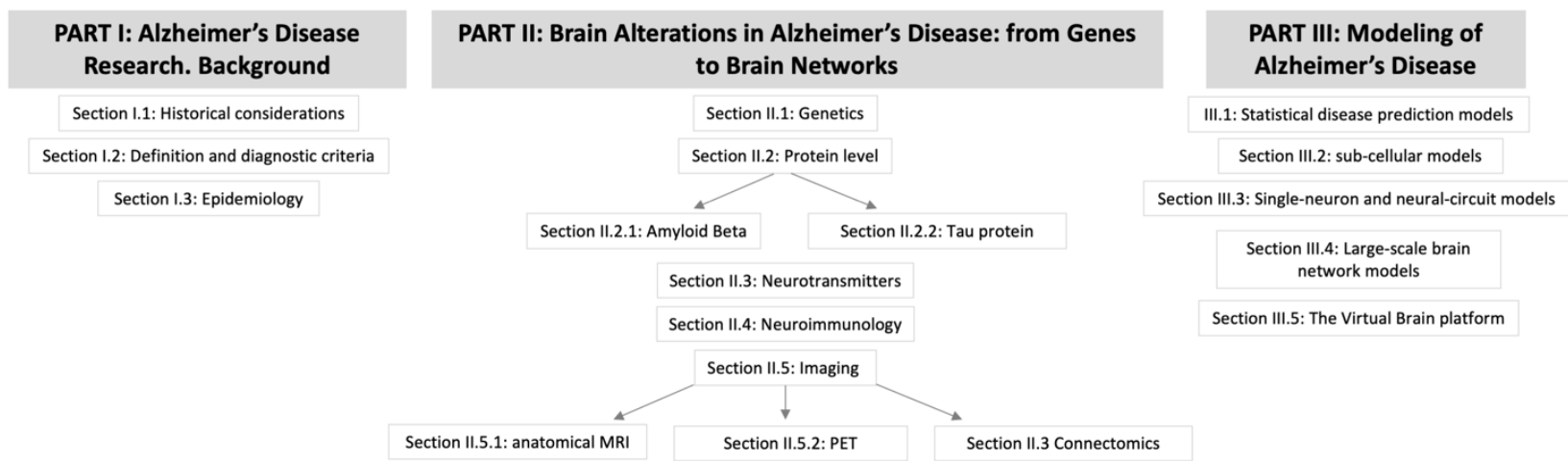

Figure 1. Flowchart for the structure of this article.

\section{„Super old", $\emptyset=97.7$ years}
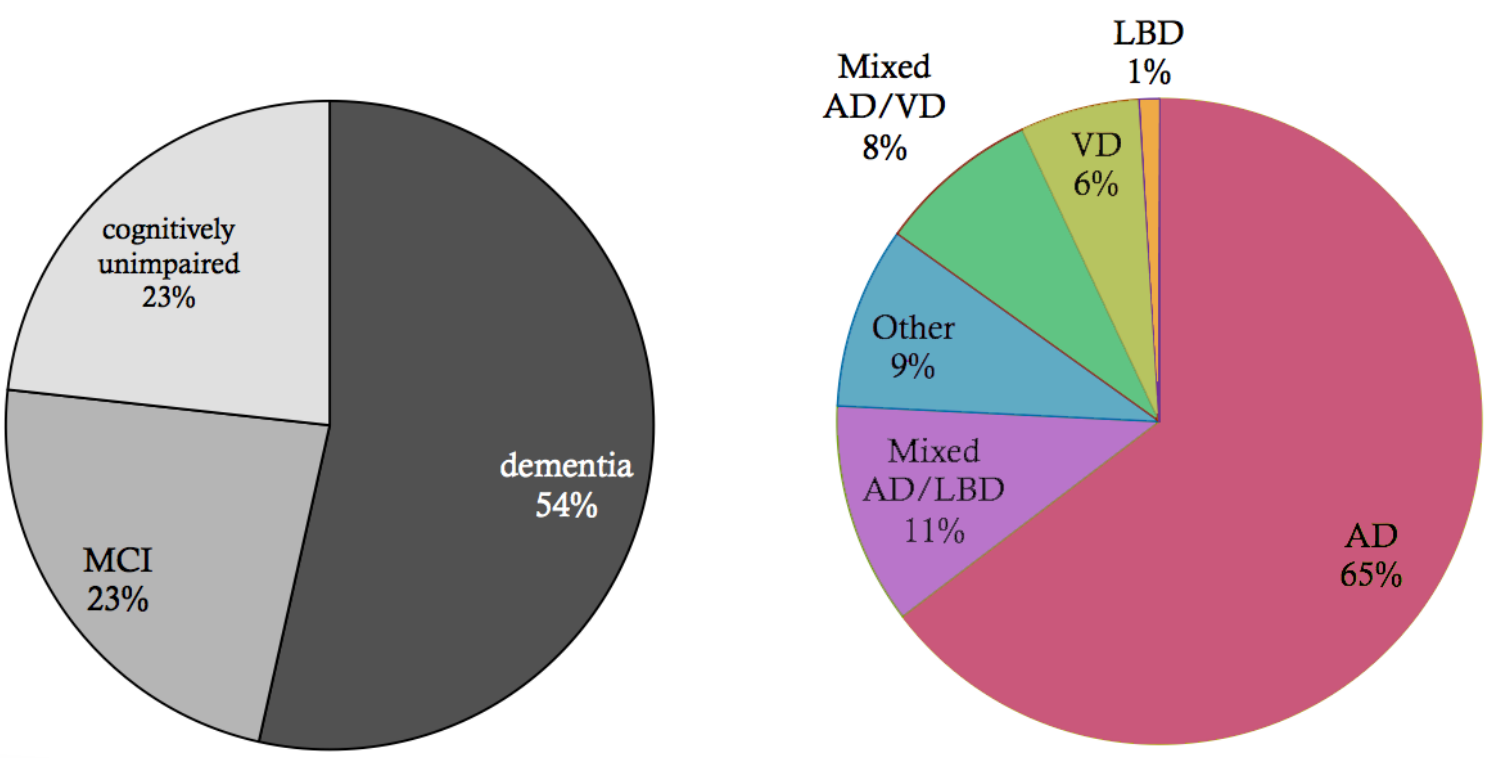

Figure 2. Basic epidemiology of different types of dementia. Data and p-values from (1). Shown is a an elderly cohort $(n=185)$ with mean age of 97.7 years in an autopsy study. On the left, we see the prevalence of the cognitive states within this cohort at time of death. In this age group, more than half of the people suffered of dementia, while a quarter suffered of mild cognitive impairment (MCI), and another quarter had no cognitive disturbances. On the right, the clinical diagnosis (ante mortem) for the subpopulation that suffered from dementia is shown. Alzheimer's Disease (AD) is the most prevalent form of dementia, however, mixed forms and other primary neurodegenerative dementias as synucleinopathies or frontotemporal lobar degeneration (FTLD) spectrum also play a role as well as vascular dementia (VD). In the post mortem analysis, the full cohort showed at least partial AD-related pathologic changes: $100 \%$ had neurofibrillary tangles of at least Braak stage I, and $63 \%$ had neuritic plaques. The mean Braak stage was in the dementia group 4.1, in the nondementia group $3.2(\mathrm{p}<0.001)$. However, the dementia group also showed a significant higher Lewy-body pathology $(\mathrm{p}=0.018)$ and TAR-DNA-binding protein $43 \mathrm{kDa}$ (TDP-43) pathology $(p<0.001)$ as well as higher rate of definitive cerebrovascular disease $(p=0.016)$. These findings indicate that in particular in the "super old", different neuropathologic changes are probably concomitant and contribute to the development of cognitive decline in dementia - in contrast to the concept of 'pure' AD as an isolated neurodegenerative disease. 


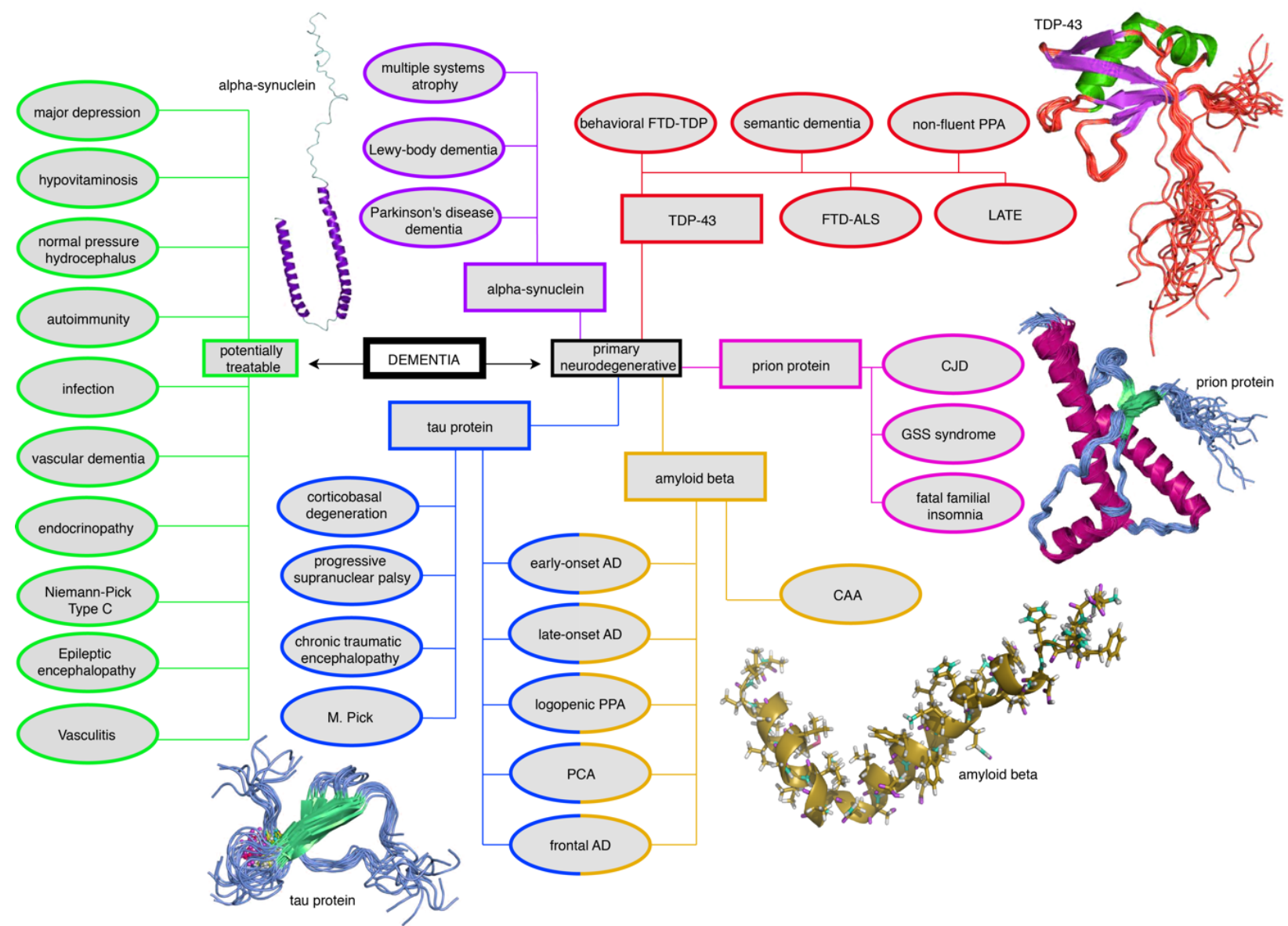

Figure 3. Mind map of the dementia syndrome and its differential diagnoses. The possible etiologies are widely spread across cerebral and systemic diseases. It is important to mention that Alzheimer's Disease (AD) may be the most common form of dementia but AD is not trivial to diagnose, in particular, if it may be indicated to forgo some invasive tests in the elderly. The exact diagnosis is however of enormous relevance because some of the possible causes of dementia are curable such as normal pressure hydrocephalus, metabolic disorders, and immunologic or infectious causes. In the clinic, most patients are diagnosed with AD, vascular dementia (VD), Lewy-body dementia, frontotemporal dementia or a mixed form thereof (Figure 2). None of the primary neurodegenerative diseases can be treated in a causal and disease-modifying way, besides the treatment of vascular dementia with general atherosclerosis therapy. The neurodegenerative diseases are sorted by their leading proteinopathy - caused by Abeta, Tau, prion protein, transactive response DNA binding protein $43 \mathrm{kDa}$ (TDP-43), and alpha synuclein (16). Protein images modified from http://www.ebi.ac.uk/. Abbreviations: FTD-TDP - frontotemporal degeneration caused by TDP-43; PPA - primary progressive aphasia; FTD-ALS - frontotemporal degeneration with amyotrophic lateral sclerosis; LATE - limbic-predominant age-related TDP-43 encephalopathy; CJD - Creutzfeldt-Jakob's disease; GSS - Gerstmann-Sträußler-Scheinker; CAA - cerebral amyloid angiopathy; PCA - posterior cortical atrophy 


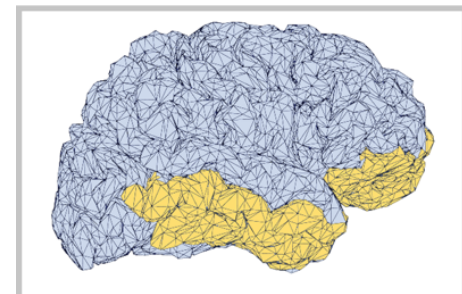

Amyloid stage A
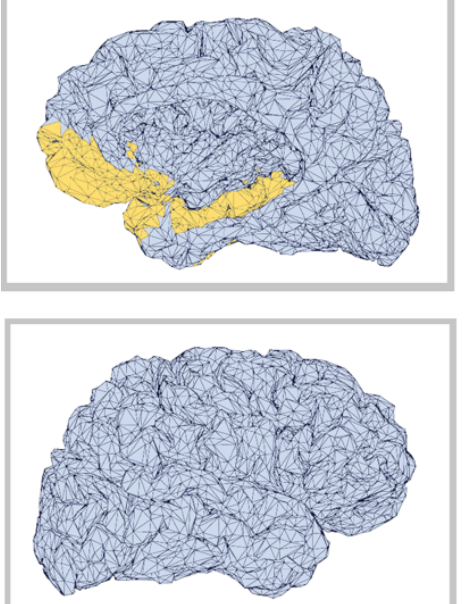

\section{Braak stages}

I+II

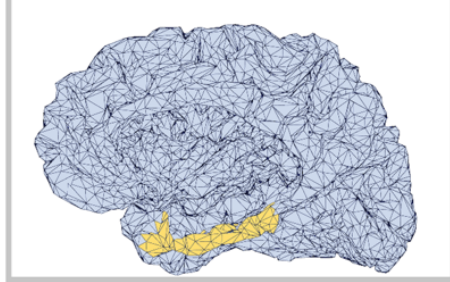

Figure 4. Visual representation of Abeta and Braak (Tau) stages $(83,84,105)$. The darker color indicates a higher load of this protein in the colored brain area. Highlighted in different colors are the regions listed in Tables 3 and 4.
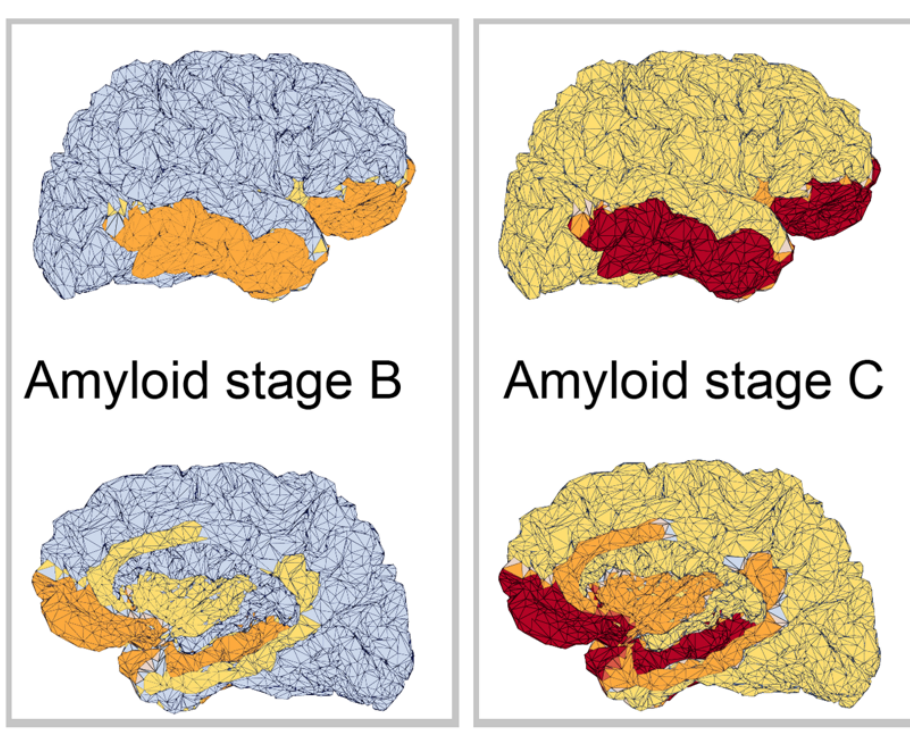

Amyloid stage C
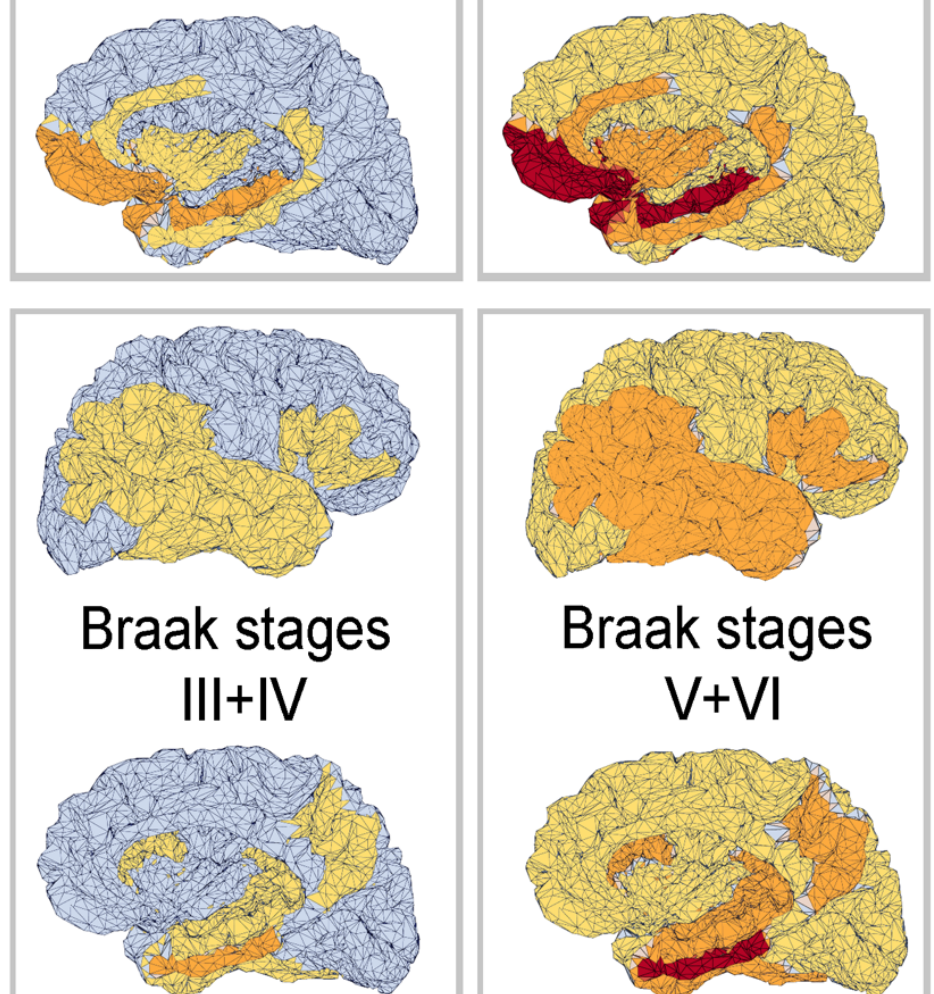

High load

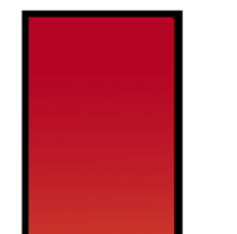

Low load 


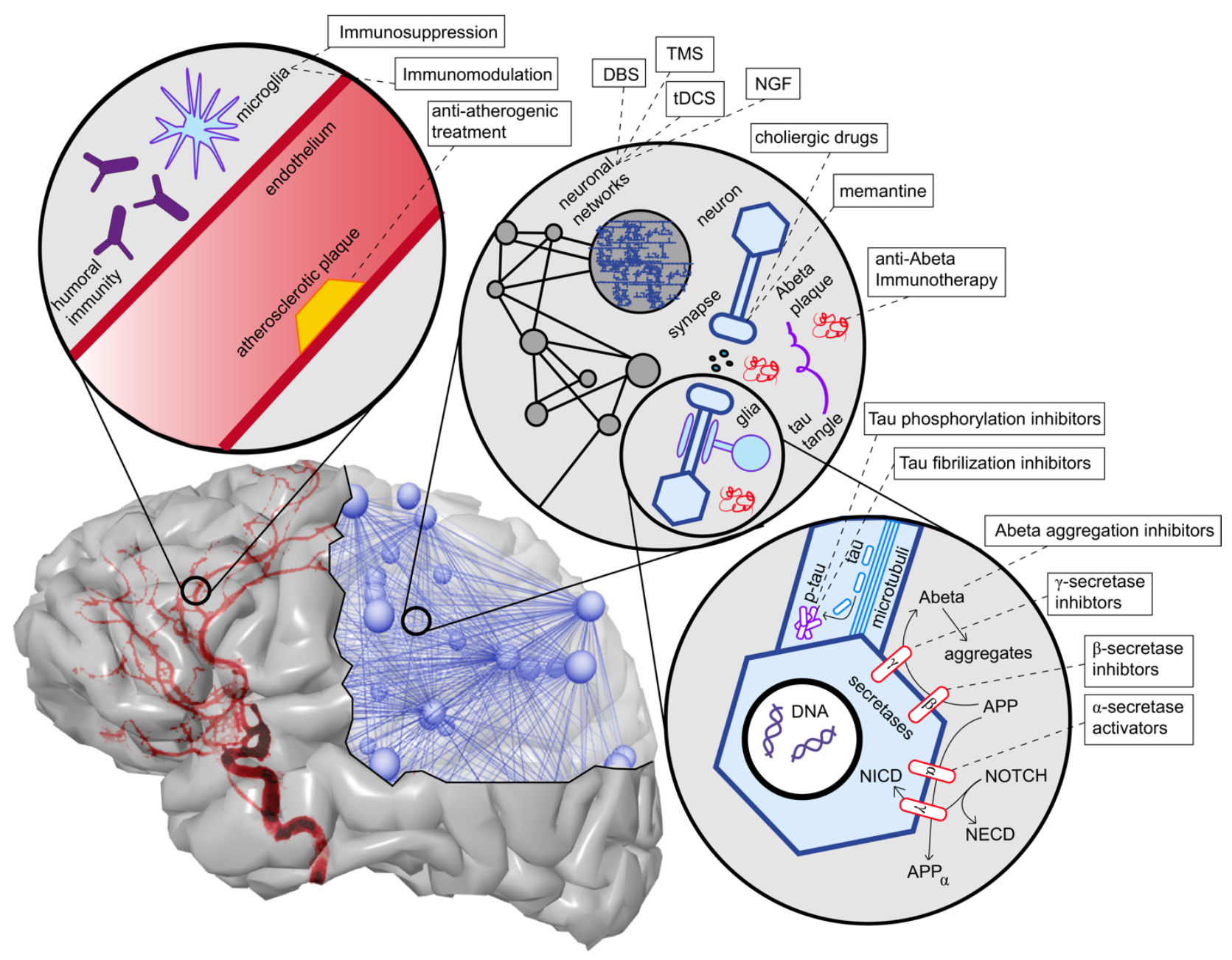

Figure 5. Overview of contributing factors in $\mathrm{AD}$ and potential intervention strategies. Shown are only the most important factors, which are also enlightened in more detail in the main text of this article. In the upper left corner, we see the neurovascular system. Both characteristics of blood vessels (e.g. atherosclerosis and endothelial dysfunction) (32) as well as aspects of the blood-brain barrier (275) play a role in AD. A particular aspect here is the role of neural immunity, both with the brain-own microglia cells as well as the effect of systemic immune cells, e.g. mediated by antibodies $(110,116)$. On the upper right corner, we see an illustration of the multi-scale network structure of the brain. Stimulation approaches as deep brain stimulation (DBS), transcranial magnetic stimulation (TMS) and transcranial direct current stimulation (tDCS) act on the larger scale of a network level, nevertheless the actual changes happen on the level of synapses. Also transmitter interventions develop their effects mainly at the micro-scale of synapses. In the lower right corner, basic molecular pathways in the extra- and intracellular space of a neuron are shown. We focused here on the processing of the two hallmark proteins Abeta and Tau as well as the Notch1 pathway, which is involved in memory (91) and plasticity (92). We illustrate the APP procession by the amyloidogenic or non-amyloidogenic way and its interaction with Notch-1 processing and, second, in the axon, the hyperphosphorylation and aggregation of Tau. A more detailed description of the named treatment strategies that are presently under development is provided in Table $\mathbf{1}$. 


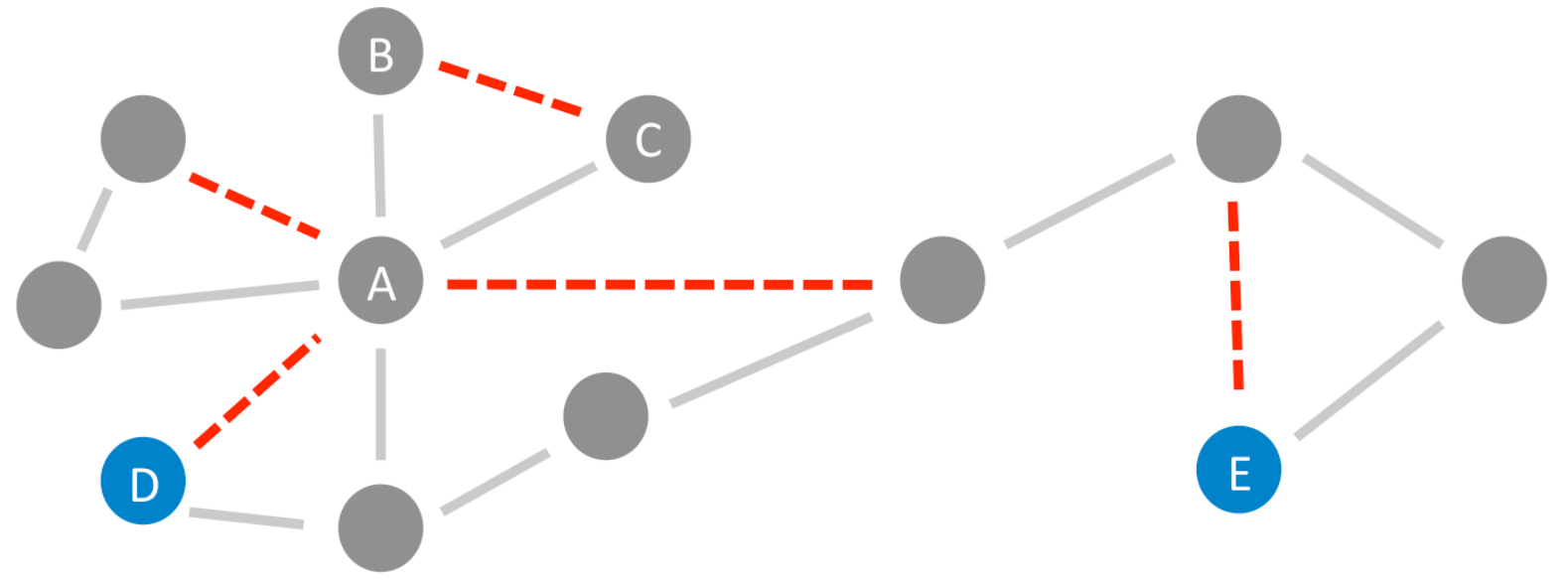

Figure 6. Neurodegeneration in Alzheimer's Disease (AD) from a network perspective. In this schematic example network, the red links (edges) are being weakened and progressively disconnected by AD. Preferentially, edges attached to nodes with high degree (hubs) are being targeted (here node A) (176-178). In addition, lower clustering in AD has repeatedly been observed $(161,179,186,187)$, i.e. links involved in triangles are broken off (here e.g. the link between nodes $\mathrm{B}$ and $\mathrm{C}$ forming the triangle A-B-C). These two "attacks" of AD on the network, lead not only to a lower clustering coefficient but also evoke a lower efficiency, defined here as the inverse of path lengths, an estimate of short and efficient connections. This lower efficiency is demonstrated in the example network by the shortest path length between the blue nodes $\mathrm{D}$ and $\mathrm{E}$ before and after the deletion of the red links (before: 4 links, after: 6 links).

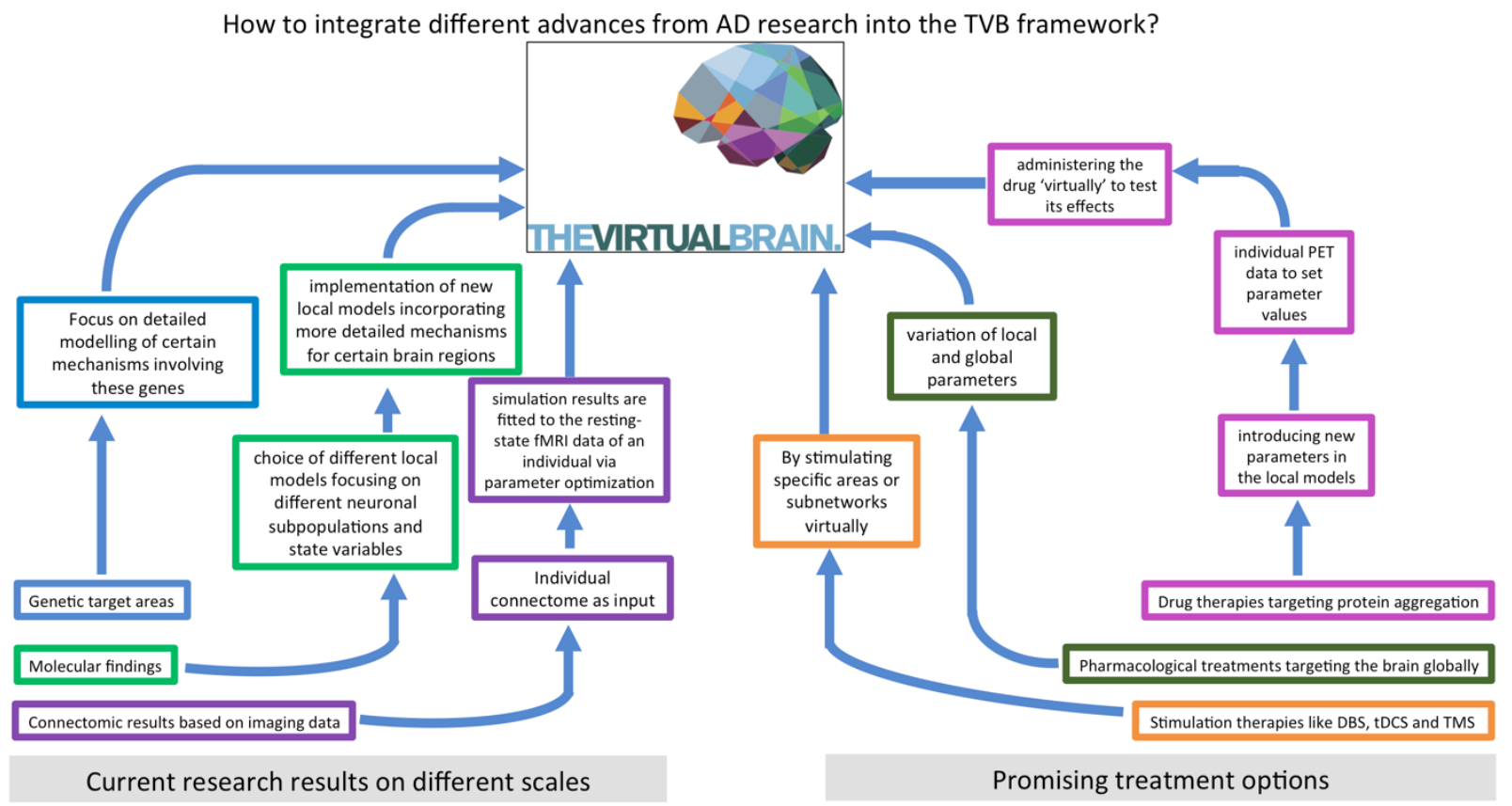

Figure 7. Potential applications of The Virtual Brain in the investigation of Alzheimer's Disease (AD). As we outline in this article, computational modeling provides a powerful tool to link empirical findings from different scales and disciplines to new insights for improved diagnostics and treatments. Abbreviations: PET - positrone emission tomography; DBS - deep brain stimulation; tDCS - transcrnial direct current stimulation; TMS - transcranial magnetic stimulation. 
TABLES

Table 1. Ongoing developments for AD treatment and therapies. Parts of the table are modified from (276-278).

\begin{tabular}{|c|c|c|c|}
\hline $\begin{array}{l}\text { Possible disease- } \\
\text { modifying treatment }\end{array}$ & $\begin{array}{l}\text { Substance } \\
\text { example }\end{array}$ & Results & References \\
\hline$\alpha$ secretase activators & $\begin{array}{l}\text { Etazolate, } \\
\text { Epigallocatechin } \\
\text { gallate }\end{array}$ & Safety, $A \beta$ aggregation $\downarrow$ & $(276,279)$ \\
\hline$\beta$ secretase inhibitors & $\begin{array}{l}\text { Pioglitazone, } \\
\text { rosiglitazone, } \\
\text { AZD3293 }\end{array}$ & $\begin{array}{l}\text { Safety, Plasma } A \beta \text { concentration } \downarrow \text { cognitive } \\
\text { benefit for diabetical patients in observational } \\
\text { study, until now no prospective clinical effect }\end{array}$ & $\begin{array}{l}(110,276 \\
280-284)\end{array}$ \\
\hline$\gamma$ secretase modulators & $\begin{array}{l}\text { Tarenflurbil, EVP- } \\
0962\end{array}$ & No clinical effect & $\begin{array}{l}(276,285 \\
286)\end{array}$ \\
\hline$\gamma$ secretase inhibitors & $\begin{array}{l}\text { Semagacestat, } \\
\text { Avagacestat }\end{array}$ & Skin cancer $\uparrow$, infections $\uparrow$, no clinical effect & $(88,90,276)$ \\
\hline $\begin{array}{l}\mathrm{A} \beta \text { aggregation } \\
\text { inhibitors }\end{array}$ & $\begin{array}{l}\text { PBT2, Tramiprosat, } \\
\text { Scylloinositol }\end{array}$ & CSF A $\beta \downarrow$, PiB PET $\downarrow$, no clinical effect & $\begin{array}{l}(73,276, \\
287)\end{array}$ \\
\hline $\begin{array}{l}\mathrm{A} \beta \text { active } \\
\text { immunotherapy }\end{array}$ & $\begin{array}{l}\text { Anti-A } \beta \text { vaccines } \\
\text { AN1792, CAD-106 }\end{array}$ & $\begin{array}{l}\text { Meningoencephalitis (AN1792), positive } \\
\text { antibody response, no clinical effect }\end{array}$ & $\begin{array}{l}(71,72,75 \\
76,276)\end{array}$ \\
\hline $\begin{array}{l}\mathrm{A} \beta \text { passive } \\
\text { immunotherapy }\end{array}$ & $\begin{array}{l}\text { Solanezumab, } \\
\text { Bapineuzumab }\end{array}$ & $\begin{array}{l}\text { Safety, questionable cognitive effect of } \\
\text { Solanezumab }\end{array}$ & $\begin{array}{l}(79,276 \\
288,289)\end{array}$ \\
\hline $\begin{array}{l}\tau \text { phosphorylation } \\
\text { inhibitors }\end{array}$ & Lithium, valproat & $\begin{array}{l}\text { High toxicity, CSF } \tau \downarrow \text { and questionable } \\
\text { cognitive effect of Lithium }\end{array}$ & $\begin{array}{l}(276,290, \\
291)\end{array}$ \\
\hline $\begin{array}{l}\tau \text { fibirillization } \\
\text { inhibtors }\end{array}$ & $\begin{array}{l}\text { Methylene blue, } \\
\text { davunetide }\end{array}$ & $\begin{array}{l}\tau \text { production } \downarrow \text {, possible cognitive effect of } \\
\text { davunetide }\end{array}$ & $(276,292)$ \\
\hline Macro-/Micronutrients & $\begin{array}{l}\text { Polyunsaturated } \\
\text { fatty acids }\end{array}$ & No clinical effect & $\begin{array}{l}(276,293- \\
295)\end{array}$ \\
\hline $\begin{array}{l}\text { Phoshphodiesterase } \\
\text { inhibitors }\end{array}$ & Cilostatol & Possible cognitive effect & $(276,296)$ \\
\hline $\begin{array}{l}\text { Tyrosine kinase } \\
\text { inhibitors }\end{array}$ & Mastinib & unclear & $(276,297)$ \\
\hline Statines & $\begin{array}{l}\text { Simvastatine, } \\
\text { atorvastatine }\end{array}$ & Unclear cognitive effects, CSF phosphor $\tau \downarrow$ & $\begin{array}{l}(276,298 \\
299)\end{array}$ \\
\hline
\end{tabular}




\begin{tabular}{|l|l|l|l|}
\hline Insulin & Intranasal insulin & FDG PET effect, possible cognitive effect & $(276,300)$ \\
\hline $\begin{array}{l}\text { NGF intracerebral } \\
\text { application }\end{array}$ & $\begin{array}{l}\text { Neurotrophic growth } \\
\text { factor }\end{array}$ & $\begin{array}{l}\text { CSF effects, gene expression effects, possible } \\
\text { cognitive effect in subgroup }\end{array}$ & $(301-303)$ \\
\hline Deep brain stimulation & n.a. & $\begin{array}{l}\text { Possible cognitive effects, highly invasive, } \\
\text { ethical issues }\end{array}$ & $(304-308)$ \\
\hline $\begin{array}{l}\text { Trancranial brain } \\
\text { stimulation }\end{array}$ & n.a. & Unclear effects & $\begin{array}{l}(232,305, \\
309-312)\end{array}$ \\
\hline
\end{tabular}

Table 2. Potentially curable causes of dementia syndromes $(16,313)$.

\begin{tabular}{|c|c|c|}
\hline Curable dementia cause & Diagnostic tool & Therapy \\
\hline Major Depression & Clinical & $\begin{array}{l}\text { Psychotherapy, anti-depressive } \\
\text { pharmacotherapy }\end{array}$ \\
\hline $\begin{array}{l}\text { Nutritive deficiency } \\
\text { (Vitamine B12, D, folic acid) }\end{array}$ & Blood & Substitution \\
\hline $\begin{array}{l}\text { Infections } \\
\text { (Lues, borreliosis, viral) }\end{array}$ & CSF, Blood, clinical, imaging & Anti-infectious \\
\hline Normal pressure hydrocephalus & Imaging, tab test & Ventriculoperitoneal shunt \\
\hline Autoimmune encephalitis & CSF, imaging & $\begin{array}{l}\text { Immunosuppression, } \\
\text { plasmapheresis }\end{array}$ \\
\hline Vasculitis & CSF, imaging, angiography & Immunosuppression \\
\hline Macroangiopathy & Imaging & $\begin{array}{l}\text { Risk factor management, } \\
\text { thrombendarteriectomy }\end{array}$ \\
\hline Microangiopathy & Imaging & Risk factor management \\
\hline Hypothyreosis & Blood & Substitution \\
\hline Niemann-Pick type C & Blood (genetics, oxysterols) & Enzyme substitution \\
\hline Epileptic encephalopathy & EEG, ex juvantibus & Anticonvulsive drugs \\
\hline
\end{tabular}


Table 3. Stages of amyloid deposition (83, 84, 105).

\begin{tabular}{|l|l|l|}
\hline Amyloid deposition - Stage A & Stage B & Stage C \\
\hline $\begin{array}{l}\text { polar and orbitofrontal prefrontal } \\
\text { cortex; polar, inferior, central and } \\
\text { ventral temporal cortex }\end{array}$ & $\begin{array}{l}\text { As stage A, additional: } \\
\text { hippocampus and gyrus } \\
\text { parahippocampalis, Amygdala, } \\
\text { posterior and anterior insula, } \\
\text { subgenual and retrosplenial } \\
\text { cingulum, ventrolateral prefrontal } \\
\text { cortex }\end{array}$ & $\begin{array}{l}\text { As stage Bditional global } \\
\text { neocortical dissemination }\end{array}$ \\
\hline
\end{tabular}

Table 4. Braak stages of Tau deposition (83-85).

\begin{tabular}{|c|c|c|c|c|}
\hline & deposition & Anatomic region & ${ }^{18}$ F-AV-14-51 PET & Diagnosis (PET) \\
\hline I & $\begin{array}{l}\text { Trans- } \\
\text { entorhinal }\end{array}$ & $\begin{array}{l}\text { transentorhinal cortex } \\
\text { (medial temporal } \\
\text { lobe }=\text { perirhinal } \\
\text { cortex }\end{array}$ & $\begin{array}{l}\text { Entorhinal cortex, } \\
\text { Hippocampus, } \\
\text { Parahippocampal cortex, } \\
(106)\end{array}$ & MCI \\
\hline II & & $\begin{array}{l}\text { entorhinal cortex } \\
\text { (lamina II) }\end{array}$ & & \\
\hline III & limbic & $\begin{array}{l}\text { hippocampus, } \\
\text { temporal allocortex }\end{array}$ & & \\
\hline IV & & $\begin{array}{l}\text { neocortical } \\
\text { association fields next } \\
\text { to hippocampus }\end{array}$ & $\begin{array}{l}\text { Isocortical spreading, particular } \\
\text { differences to MCI in precuneus, } \\
\text { prefrontal, temporal and inferior parietal } \\
\text { cortex (106) }\end{array}$ & AD \\
\hline $\mathrm{V}$ & isocortical & $\begin{array}{l}\text { Neocortex, } \\
\text { spreading to } \\
\text { dorsolateral }\end{array}$ & & \\
\hline VI & & $\begin{array}{l}\text { Primary sensory and } \\
\text { motor areas }\end{array}$ & & \\
\hline
\end{tabular}


Table 5: Overview of brain imaging studies and their results in Alzheimer's disease for the different modalities EEG, MEG, (f)MRI and PET.

\begin{tabular}{|c|c|c|c|c|}
\hline \multicolumn{2}{|c|}{$\begin{array}{l}\text { Changes in AD imaging compared } \\
\text { to healthy controls }\end{array}$} & \multirow{2}{*}{$\begin{array}{l}\text { Imaging } \\
\text { modality } \\
\text { EEG }\end{array}$} & \multirow{2}{*}{$\begin{array}{l}\text { Reference for evidence } \\
(314,315)\end{array}$} & \multirow[t]{2}{*}{ Contradicting evidence } \\
\hline \multirow{13}{*}{$\begin{array}{l}\text { global } \\
\text { connectome } \\
\text { changes }\end{array}$} & \multirow{4}{*}{$\begin{array}{l}\text { decreased global } \\
\text { efficiency / longer } \\
\text { characteristic path } \\
\text { length }\end{array}$} & & & \\
\hline & & MEG & \multicolumn{2}{|l|}{$(316)$} \\
\hline & & fMRI & $\begin{array}{l}\text { Amnestic MCI: (186); } \\
\text { AD: }(317,318)\end{array}$ & $\begin{array}{l}\text { similar characteristic path length as } \\
\text { controls (319) }\end{array}$ \\
\hline & & sMRI & \multicolumn{2}{|c|}{$(188,189,192,193)$ (not significant); $(320,321)$} \\
\hline & $\begin{array}{l}\text { decreased averaged } \\
\text { local efficiency }\end{array}$ & sMRI & $(189)$ & $\begin{array}{l}\text { increased averaged local efficiency in } \\
\text { fMRI ( } 318)\end{array}$ \\
\hline & \multirow[t]{4}{*}{$\begin{array}{l}\text { decreased global } \\
\text { clustering }\end{array}$} & EEG & \multicolumn{2}{|l|}{$(314)$} \\
\hline & & MEG & $(176)$ & $\begin{array}{l}\text { preserved clustering coefficient in } \\
\text { EEG (315) }\end{array}$ \\
\hline & & fMRI & $\begin{array}{l}\text { Amnestic MCI: (186); } \\
\text { AD: }(161,319)\end{array}$ & $\begin{array}{l}\text { increased global clustering in fMRI } \\
\text { (318); unchanged global clustering in } \\
\text { fMRI ( } 317)\end{array}$ \\
\hline & & sMRI & $\begin{array}{l}(161,187,189)(\text { not } \\
\text { significant) }\end{array}$ & $\begin{array}{l}\text { increased clustering coefficient in } \\
\text { structural MRI }(320,321)\end{array}$ \\
\hline & $\begin{array}{l}\text { decreased network } \\
\text { robustness }\end{array}$ & MEG & \multicolumn{2}{|l|}{$(244)$} \\
\hline & $\begin{array}{l}\text { altered modular } \\
\text { structure }\end{array}$ & fMRI & \multicolumn{2}{|c|}{ Amnestic MCI: (186); AD: $(161,181)$} \\
\hline & & sMRI & \multicolumn{2}{|l|}{$(161,187)$} \\
\hline & $\begin{array}{l}\text { rich club } \\
\text { organization } \\
\text { affected }\end{array}$ & sMRI & \multicolumn{2}{|l|}{$(161,177,187)$} \\
\hline \multirow[t]{3}{*}{$\begin{array}{l}\text { network } \\
\text { changes }\end{array}$} & $\begin{array}{l}\mathrm{DMN} \text { is attacked } \\
\text { by } \mathrm{AD}\end{array}$ & fMRI & $(157-163)$ & $\begin{array}{l}\text { increased local efficiency in the DMN } \\
\text { in fMRI ( } 318)\end{array}$ \\
\hline & & sMRI & \multicolumn{2}{|l|}{$(161,163,193)$} \\
\hline & $\begin{array}{l}\text { core of the network } \\
\text { is most affected }\end{array}$ & $\begin{array}{l}\text { sMRI, } \\
\text { MEG } \\
\text { and } \\
\text { fMRI }\end{array}$ & $(191)$ & $\begin{array}{l}\text { predominantly low-degree regions } \\
\text { outside the core loose connectivity in } \\
\text { structural MRI (192) }\end{array}$ \\
\hline
\end{tabular}




\begin{tabular}{|c|c|c|c|c|}
\hline & $\begin{array}{l}\text { increased } \\
\text { connectivity for } \\
\text { sensorimotor } \\
\text { system }\end{array}$ & $\begin{array}{l}\text { sMRI, } \\
\text { MEG } \\
\text { and } \\
\text { fMRI }\end{array}$ & (191) & \\
\hline \multirow[t]{9}{*}{$\begin{array}{l}\text { Regional } \\
\text { connectome } \\
\text { changes }\end{array}$} & $\begin{array}{l}\text { decreased } \\
\text { connectivity in the } \\
\text { insula }\end{array}$ & fMRI & \multicolumn{2}{|l|}{ (181) } \\
\hline & $\begin{array}{l}\text { decreased } \\
\text { connectivity in the } \\
\text { posteromedial } \\
\text { cortex }\end{array}$ & fMRI & \multicolumn{2}{|l|}{ (182) } \\
\hline & $\begin{array}{l}\text { decreased } \\
\text { connectivity in the } \\
\text { medial temporal } \\
\text { cortex }\end{array}$ & fMRI & \multicolumn{2}{|l|}{ (183) } \\
\hline & $\begin{array}{l}\text { decreased } \\
\text { connectivity in the } \\
\text { amygdala }\end{array}$ & fMRI & \multicolumn{2}{|l|}{$(184,185)$} \\
\hline & $\begin{array}{l}\text { decreased } \\
\text { connectivity in the } \\
\text { parahippocampal } \\
\text { area }\end{array}$ & sMRI & \multicolumn{2}{|l|}{ (174) } \\
\hline & $\begin{array}{l}\text { decreased } \\
\text { connectivity in } \\
\text { frontal regions }\end{array}$ & sMRI & (188) & $\begin{array}{l}\text { increased connectivity within frontal } \\
\text { areas in fMRI (319) }\end{array}$ \\
\hline & $\begin{array}{l}\text { disconnection of } \\
\text { the precuneus, } \\
\text { parietal and } \\
\text { temporal areas }\end{array}$ & fMRI & \multicolumn{2}{|l|}{ Amnestic MC: (186) } \\
\hline & $\begin{array}{l}\text { reduced local } \\
\text { clustering for } \\
\text { hippocampus }\end{array}$ & fMRI & \multicolumn{2}{|l|}{ (319) } \\
\hline & $\begin{array}{l}\text { decreased } \\
\text { connectivity within } \\
\text { the temporal lobe }\end{array}$ & fMRI & \multicolumn{2}{|l|}{ (319) } \\
\hline
\end{tabular}




\begin{tabular}{|c|c|c|c|c|}
\hline \multirow[t]{6}{*}{$\begin{array}{l}\text { regional } \\
\text { atrophy }\end{array}$} & $\begin{array}{l}\text { Atrophy in the } \\
\text { hippocampus }\end{array}$ & sMRI & \multicolumn{2}{|c|}{ Mild dementia stage of AD: $(322,323)$; amnestic MCI: (324) } \\
\hline & $\begin{array}{l}\text { Atrophy and } \\
\text { thinning of the } \\
\text { entorhinal cortex }\end{array}$ & sMRI & \multicolumn{2}{|l|}{$(325-329)$} \\
\hline & $\begin{array}{l}\text { Reduction of } \\
\text { amygdala volume }\end{array}$ & sMRI & \multicolumn{2}{|l|}{$(330,331)$} \\
\hline & $\begin{array}{l}\text { Volume loss in the } \\
\text { thalamus }\end{array}$ & sMRI & \multicolumn{2}{|l|}{$(332,333)$} \\
\hline & $\begin{array}{l}\text { Reduction in } \\
\text { caudate nucleus } \\
\text { volume }\end{array}$ & sMRI & \multicolumn{2}{|l|}{$(334,335)$} \\
\hline & $\begin{array}{l}\text { Atrophy in the } \\
\text { nucleus accumbens }\end{array}$ & sMRI & \multicolumn{2}{|l|}{$(333,336)$} \\
\hline \multirow[t]{3}{*}{ Tau PET } & $\begin{array}{l}\text { Global neocortical } \\
\text { Tau binding } \\
\text { increased }\end{array}$ & $\begin{array}{l}{ }^{18} \mathrm{~F}-\mathrm{AV}- \\
1451\end{array}$ & \multicolumn{2}{|l|}{$(106,133)$} \\
\hline & $\begin{array}{l}\text { Early Braak stage } \\
\text { Tau binding } \\
\text { increased }\end{array}$ & $\begin{array}{l}{ }^{18} \mathrm{~F}-\mathrm{AV}- \\
1451 \\
{ }^{11} \mathrm{C}- \\
\text { PBB3 }\end{array}$ & $\begin{array}{l}\text { Entorhinal cortex in } \\
\text { MCI: (106); Precuneus } \\
\text { and lateral parietal in } \\
\text { inherited AD: }(141) \text {; } \\
\text { lateral and medial } \\
\text { frontal cortex in AD: } \\
\text { (132); orbitofrontal } \\
\text { cortex in AD }\left({ }^{11} \mathrm{C}-\right. \\
\text { PBB3): (104); middle } \\
\text { to high Braak stages } \\
\text { (139) }\end{array}$ & $\begin{array}{l}\text { Increased Tau binding in older } \\
\text { healthy controls' temporal and } \\
\text { retrosplenial cortex (132) }\end{array}$ \\
\hline & $\begin{array}{l}\text { Tau in network } \\
\text { hubs }\end{array}$ & $\begin{array}{l}{ }^{18} \mathrm{~F}-\mathrm{AV}- \\
1451 \\
{ }^{11} \mathrm{C}- \\
\text { PBB3 }\end{array}$ & $(95,104)$ & $\begin{array}{l}\text { Low consistency between atrophy and } \\
\text { Tau deposition in atypical } \mathrm{AD}\left({ }^{18} \mathrm{~F}-\right. \\
\text { AV-1451) (134) }\end{array}$ \\
\hline \multirow[t]{2}{*}{ Abeta PET } & $\begin{array}{l}\text { Global Abeta } \\
\text { binding increased }\end{array}$ & $\begin{array}{l}{ }^{18} \mathrm{~F}-\mathrm{AV}- \\
45 \\
\text { (Florbeta } \\
\text { pir) }\end{array}$ & \multicolumn{2}{|l|}{ Visual rating: $(140,142)$} \\
\hline & $\begin{array}{l}\text { Early Braak stage } \\
\text { Abeta binding } \\
\text { increased }\end{array}$ & $\begin{array}{l}\text { Florbetab } \\
\text { en }\left({ }^{18} \mathrm{~F}\right), \\
{ }^{11} \mathrm{C}-\mathrm{PIB}\end{array}$ & $\begin{array}{l}\text { Inferior frontal cortex } \\
\text { and precuneus (144); } \\
\text { striatum in hereditary } \\
P S E N 1 \text { patients }(62) \\
\text { and PSEN1/APP } \\
\text { patients (63); (143) }\end{array}$ & $\begin{array}{l}\text { middle to high Braak stages in } \mathrm{HC} \text {, } \\
\text { but age-related and associated with } \\
\text { ApoE: with }{ }^{11} \mathrm{C}-\mathrm{PIB}:(145) \text {, meta- } \\
\text { analysis: }(146) \text {; medial temporal lobe } \\
\text { in HC: (147) }\end{array}$ \\
\hline
\end{tabular}




\begin{tabular}{|c|c|c|c|c|}
\hline & Abeta binding & ${ }^{18} \mathrm{~F}-\mathrm{AV}-$ & \multicolumn{2}{|c|}{ Hubs of DMN including hippocampus: (337) } \\
\hline \multirow[t]{2}{*}{ Glucose PET } & $\begin{array}{l}\text { (left) } \\
\text { temporoparietal } \\
\text { hypometabolism }\end{array}$ & ${ }^{18}$-FDG & $\begin{array}{l}\text { Left precuneus, } \\
\text { posterior cingulate and } \\
\text { superior parietal cortex } \\
\text { in MCI-to-AD } \\
\text { converters (148), } \\
\text { bilaterally in (149), and } \\
\text { ApoE } \varepsilon 4 \text { carriers (150); } \\
\text { temporal, angular and } \\
\text { posterior cingular areas } \\
\text { (151); frontal, posterior } \\
\text { temporal, and parietal } \\
\text { cortex (152) }\end{array}$ & $\begin{array}{l}\text { Age-related temporal } \\
\text { hypometabolism in HC (145); low } \\
\text { sensitivity in meta-analysis for } \\
\text { differentiation of MCI converters } \\
\text { (154) }\end{array}$ \\
\hline & $\begin{array}{l}\text { Hypometabolism } \\
\text { associated to Tau }\end{array}$ & ${ }^{18}$-FDG & $\begin{array}{l}\text { Hypometabolism only } \\
\text { in presence of Abeta in } \\
\text { Tau-positive regions } \\
\text { (153) }\end{array}$ & $\begin{array}{l}\text { Hypermetabolism caused by low Tau } \\
\text { burden in absence of Abeta (153) }\end{array}$ \\
\hline
\end{tabular}

\section{CONFLICT OF INTEREST}

The authors declare that the research was conducted in the absence of any commercial or financial relationships that could be construed as a potential conflict of interest.

\section{AUTHOR CONTRIBUTIONS}

All authors have made substantial intellectual contributions to this work and approved it for publication. LS and PR developed the idea and concept for this article. LS wrote the manuscript with contribution of JMM, RKP, PT, TL, LM, KB and PR. MH, AS, ARM and PR contributed to the interpretation of the results, figure development, and revision of the manuscript.

\section{FUNDING}

We acknowledge support by EU H2020 826421, 785907; 945539, ERC 683049; German Research Foundation CRC 1315, CRC 936, CRC-TRR 295 and RI 2073/6-1; Berlin Institute of Health \& Foundation Charité, Johanna Quandt Excellence Initiative.

We acknowledge support from the German Research Foundation (DFG) and the Open Access Publication Fund of Charité-Universitätsmedizin Berlin. 


\section{REFERENCES}

1. Robinson JL, Corrada MM, Kovacs GG, Dominique M, Caswell C, Xie SX, et al. NonAlzheimer's contributions to dementia and cognitive resilience in The 90+ Study. Acta Neuropathol. 2018;136(3):377-88.

2. Alzheimer's Association. 2019 Alzheimer's disease facts and figures. Alzheimer's \& Dementia. 2019;15(3):321-87.

3. Alzheimer's Association. 2018 Alzheimer's disease facts and figures. Alzheimer's \& Dementia. 2018;14(3):367-429.

4. Bachurin SO, Bovina EV, Ustyugov AA. Drugs in Clinical Trials for Alzheimer's Disease: The Major Trends. Med Res Rev. 2017.

5. Selkoe DJ, Hardy J. The amyloid hypothesis of Alzheimer's disease at 25 years. EMBO Mol Med. 2016;8(6):595-608.

6. Schorer CE. Historical Essay: Kraepelin's Description of Alzheimer's Disease. The International Journal of Aging and Human Development. 1985;21(3):235-8.

7. Kendler KS. An historical framework for psychiatric nosology. Psychol Med. 2009;39(12):1935-41.

8. Alzheimer A. Über eigenartige Krankheitsfälle des späteren Alters. Zeitschrift für die gesamte Neurologie und Psychiatrie. 1911;4(1):356-85.

9. Alzheimer A. Uber eine eigenartige Erkrankung der Hirnrinde. Zentralbl Nervenh Psych. 1907;18:177-9.

10. Müller U, Winter P, Graeber MB. A presenilin 1 mutation in the first case of Alzheimer's disease. The Lancet Neurology. 2013;12(2):129-30.

11. Bloom GS. Amyloid- $\beta$ and tau: The trigger and bullet in alzheimer disease pathogenesis. JAMA Neurology. 2014;71(4):505-8.

12. Jellinger KA. Neuropathological staging of Alzheimer-related lesions: the challenge of establishing relations to age. Neurobiol Aging. 1997;18(4):369-75; discussion 89-92.

13. Hyman BT, Phelps CH, Beach TG, Bigio EH, Cairns NJ, Carrillo MC, et al. National Institute on Aging-Alzheimer's Association guidelines for the neuropathologic assessment of Alzheimer's disease. Alzheimer's \& Dementia: The Journal of the Alzheimer's Association. 2012;8(1):1-13.

14. Nelson PT, Alafuzoff I, Bigio EH, Bouras C, Braak H, Cairns NJ, et al. Correlation of Alzheimer disease neuropathologic changes with cognitive status: a review of the literature. $\mathrm{J}$ Neuropathol Exp Neurol. 2012;71(5):362-81. 
15. Jack CR, Jr., Bennett DA, Blennow K, Carrillo MC, Dunn B, Haeberlein SB, et al. NIAAA Research Framework: Toward a biological definition of Alzheimer's disease. Alzheimer's \& Dementia: The Journal of the Alzheimer's Association. 2018;14(4):535-62.

16. Wallesch CW, Förstl H. Demenzen: Thieme; 2012.

17. McKhann G, Drachman D, Folstein M, Katzman R, Price D, Stadlan EM. Clinical diagnosis of Alzheimer's disease. Report of the NINCDS-ADRDA Work Group* under the auspices of Department of Health and Human Services Task Force on Alzheimer's Disease. 1984;34(7):939-.

18. McKhann GM, Knopman DS, Chertkow H, Hyman BT, Jack CR, Jr., Kawas CH, et al. The diagnosis of dementia due to Alzheimer's disease: recommendations from the National Institute on Aging-Alzheimer's Association workgroups on diagnostic guidelines for Alzheimer's disease. Alzheimer's \& dementia : the journal of the Alzheimer's Association. 2011;7(3):263-9.

19. Blennow K, de Leon MJ, Zetterberg H. Alzheimer's disease. Lancet (London, England). 2006;368(9533):387-403.

20. Stern Y. Cognitive reserve in ageing and Alzheimer's disease. Lancet Neurol. 2012;11(11):1006-12.

21. Gauthier S, Zhang H, Ng KP, Pascoal TA, Rosa-Neto P. Impact of the biological definition of Alzheimer's disease using amyloid, tau and neurodegeneration (ATN): what about the role of vascular changes, inflammation, Lewy body pathology? Translational neurodegeneration. 2018;7:12.

22. Cure S, Abrams K, Belger M, Dell'agnello G, Happich M. Systematic literature review and meta-analysis of diagnostic test accuracy in Alzheimer's disease and other dementia using autopsy as standard of truth. J Alzheimers Dis. 2014;42(1):169-82.

23. Robinson JL, Lee EB, Xie SX, Rennert L, Suh E, Bredenberg C, et al. Neurodegenerative disease concomitant proteinopathies are prevalent, age-related and APOE4-associated. Brain. 2018.

24. Petersen RC, Caracciolo B, Brayne C, Gauthier S, Jelic V, Fratiglioni L. Mild cognitive impairment: a concept in evolution. Journal of internal medicine. 2014;275(3):214-28.

25. Rabin LA, Smart CM, Crane PK, Amariglio RE, Berman LM, Boada M, et al. Subjective Cognitive Decline in Older Adults: An Overview of Self-Report Measures Used Across 19 International Research Studies. Journal of Alzheimer's disease : JAD. 2015;48 Suppl 1(0 1):S63S86.

26. Cheng YW, Chen TF, Chiu MJ. From mild cognitive impairment to subjective cognitive decline: conceptual and methodological evolution. Neuropsychiatr Dis Treat. 2017;13:491-8.

27. Ashraf GM, Chibber S, Mohammad, Zaidi SK, Tabrez S, Ahmad A, et al. Recent Updates on the Association Between Alzheimer's Disease and Vascular Dementia. Med Chem. 2016;12(3):226-37. 
28. Leyhe T, Reynolds CF, 3rd, Melcher T, Linnemann C, Kloppel S, Blennow K, et al. A common challenge in older adults: Classification, overlap, and therapy of depression and dementia. Alzheimers Dement. 2017;13(1):59-71.

29. APA APA. Diagnostic and Statistical Manual of Mental Disorders. 5th ed. Washington, D.C.2013.

30. Bermel RA. Unravelling neurodegeneration in multiple sclerosis. The Lancet Neurology. 2017;16(10):764-6.

31. Fiest KM, Jette N, Roberts JI, Maxwell CJ, Smith EE, Black SE, et al. The Prevalence and Incidence of Dementia: a Systematic Review and Meta-analysis. Can J Neurol Sci. 2016;43 Suppl 1:S3-S50.

32. Love S, Miners JS. Cerebrovascular disease in ageing and Alzheimer's disease. Acta Neuropathol. 2016;131(5):645-58.

33. Santos CY, Snyder PJ, Wu W-C, Zhang M, Echeverria A, Alber J. Pathophysiologic relationship between Alzheimer's disease, cerebrovascular disease, and cardiovascular risk: A review and synthesis. Alzheimer's \& Dementia: Diagnosis, Assessment \& Disease Monitoring. 2017;7:69-87.

34. Banerjee G, Ambler G, Keshavan A, Paterson RW, Foiani MS, Toombs J, et al. Cerebrospinal Fluid Biomarkers in Cerebral Amyloid Angiopathy. J Alzheimers Dis. 2020.

35. Lindsay J, Laurin D, Verreault R, Hebert R, Helliwell B, Hill GB, et al. Risk factors for Alzheimer's disease: a prospective analysis from the Canadian Study of Health and Aging. Am J Epidemiol. 2002;156(5):445-53.

36. Larson EB, Wang L, Bowen JD, et al. EXercise is associated with reduced risk for incident dementia among persons 65 years of age and older. Annals of Internal Medicine. 2006;144(2):7381.

37. Pasquier F, Boulogne A, Leys D, Fontaine P. Diabetes mellitus and dementia. Diabetes Metab. 2006;32(5 Pt 1):403-14.

38. Shepardson NE, Shankar GM, Selkoe DJ. Cholesterol level and statin use in Alzheimer disease: I. Review of epidemiological and preclinical studies. Arch Neurol. 2011;68(10):1239-44.

39. Shepardson NE, Shankar GM, Selkoe DJ. Cholesterol level and statin use in Alzheimer disease: II. Review of human trials and recommendations. Arch Neurol. 2011;68(11):1385-92.

40. Reitz C, Brayne C, Mayeux R. Epidemiology of Alzheimer disease. Nature reviews Neurology. 2011;7(3):137-52.

41. Santos CY, Snyder PJ, Wu WC, Zhang M, Echeverria A, Alber J. Pathophysiologic relationship between Alzheimer's disease, cerebrovascular disease, and cardiovascular risk: A review and synthesis. Alzheimers Dement (Amst). 2017;7:69-87. 
42. Mahley RW. Apolipoprotein E: from cardiovascular disease to neurodegenerative disorders. J Mol Med (Berl). 2016;94(7):739-46.

43. Suri S, Heise V, Trachtenberg AJ, Mackay CE. The forgotten APOE allele: a review of the evidence and suggested mechanisms for the protective effect of APOE varepsilon2. Neurosci Biobehav Rev. 2013;37(10 Pt 2):2878-86.

44. Rohn TT. Is apolipoprotein E4 an important risk factor for vascular dementia? Int J Clin Exp Pathol. 2014;7(7):3504-11.

45. Norton S, Matthews FE, Barnes DE, Yaffe K, Brayne C. Potential for primary prevention of Alzheimer's disease: an analysis of population-based data. Lancet Neurol. 2014;13(8):788-94.

46. Siegerink B, Rohmann JL. Impact of your results: Beyond the relative risk. Res Pract Thromb Haemost. 2018;2(4):653-7.

47. Sannerud R, Esselens C, Ejsmont P, Mattera R, Rochin L, Tharkeshwar AK, et al. Restricted Location of PSEN $2 / \gamma$-Secretase Determines Substrate Specificity and Generates an Intracellular A $\beta$ Pool. Cell. 2016;166(1):193-208.

48. Ertekin-Taner N. Genetics of Alzheimer's disease: a centennial review. Neurol Clin. 2007;25(3):611-67, v.

49. Lanoiselée H-M, Nicolas G, Wallon D, Rovelet-Lecrux A, Lacour M, Rousseau S, et al. APP, PSEN1, and PSEN2 mutations in early-onset Alzheimer disease: A genetic screening study of familial and sporadic cases. PLoS Med. 2017;14(3):e1002270.

50. Sun L, Zhou R, Yang G, Shi Y. Analysis of 138 pathogenic mutations in presenilin-1 on the in vitro production of $A \beta 42$ and $A \beta 40$ peptides by $\gamma$-secretase. Proc Natl Acad Sci U S A. 2017;114(4):E476-E85.

51. Pedersen NL, Gatz M, Berg S, Johansson B. How heritable is Alzheimer's disease late in life? Findings from Swedish twins. Ann Neurol. 2004;55(2):180-5.

52. Ridge PG, Hoyt KB, Boehme K, Mukherjee S, Crane PK, Haines JL, et al. Assessment of the genetic variance of late-onset Alzheimer's disease. Neurobiol Aging. 2016;41:200.e13-.e20.

53. Wainaina MN, Chen Z, Zhong C. Environmental factors in the development and progression of late-onset Alzheimer's disease. Neuroscience bulletin. 2014;30(2):253-70.

54. Grant WB, Campbell A, Itzhaki RF, Savory J. The significance of environmental factors in the etiology of Alzheimer's disease. J Alzheimers Dis. 2002;4(3):179-89.

55. Cuyvers E, Sleegers K. Genetic variations underlying Alzheimer's disease: evidence from genome-wide association studies and beyond. Lancet Neurol. 2016;15(8):857-68.

56. Speed D, Cai N, Consortium U, Johnson MR, Nejentsev S, Balding DJ. Reevaluation of SNP heritability in complex human traits. Nat Genet. 2017;49(7):986-92. 
57. Visscher PM, Wray NR, Zhang Q, Sklar P, McCarthy MI, Brown MA, et al. 10 Years of GWAS Discovery: Biology, Function, and Translation. Am J Hum Genet. 2017;101(1):5-22.

58. Kunkle BW, Grenier-Boley B, Sims R, Bis JC, Damotte V, Naj AC, et al. Genetic metaanalysis of diagnosed Alzheimer's disease identifies new risk loci and implicates $\mathrm{A} \beta$, tau, immunity and lipid processing. Nat Genet. 2019;51(3):414-30.

59. Jansen IE, Savage JE, Watanabe K, Bryois J, Williams DM, Steinberg S, et al. Genomewide meta-analysis identifies new loci and functional pathways influencing Alzheimer's disease risk. Nat Genet. 2019;51(3):404-13.

60. Marioni RE, Harris SE, Zhang Q, McRae AF, Hagenaars SP, Hill WD, et al. GWAS on family history of Alzheimer's disease. Transl Psychiatry. 2018;8(1):99.

61. Andrews SJ, Fulton-Howard B, Goate A. Interpretation of risk loci from genome-wide association studies of Alzheimer's disease. Lancet Neurol. 2020;19(4):326-35.

62. Klunk WE, Price JC, Mathis CA, Tsopelas ND, Lopresti BJ, Ziolko SK, et al. Amyloid deposition begins in the striatum of presenilin-1 mutation carriers from two unrelated pedigrees. $\mathrm{J}$ Neurosci. 2007;27(23):6174-84.

63. Villemagne VL, Ataka S, Mizuno T, Brooks WS, Wada Y, Kondo M, et al. High striatal amyloid beta-peptide deposition across different autosomal Alzheimer disease mutation types. Arch Neurol. 2009;66(12):1537-44.

64. Jack CR, Jr., Lowe VJ, Weigand SD, Wiste HJ, Senjem ML, Knopman DS, et al. Serial PIB and MRI in normal, mild cognitive impairment and Alzheimer's disease: implications for sequence of pathological events in Alzheimer's disease. Brain. 2009;132(Pt 5):1355-65.

65. Walsh DM, Selkoe DJ. A beta oligomers - a decade of discovery. J Neurochem. 2007;101(5):1172-84.

66. Hardy J, Selkoe DJ. The amyloid hypothesis of Alzheimer's disease: progress and problems on the road to therapeutics. Science. 2002;297(5580):353-6.

67. Robinson JL, Lee EB, Xie SX, Rennert L, Suh E, Bredenberg C, et al. Neurodegenerative disease concomitant proteinopathies are prevalent, age-related and APOE4-associated. Brain. 2018;141(7):2181-93.

68. Montine TJ, Phelps CH, Beach TG, Bigio EH, Cairns NJ, Dickson DW, et al. National Institute on Aging-Alzheimer's Association guidelines for the neuropathologic assessment of Alzheimer's disease: a practical approach. Acta neuropathologica. 2012;123(1):1-11.

69. Kovacs GG. Invited review: Neuropathology of tauopathies: principles and practice. Neuropathology and applied neurobiology. 2015;41(1):3-23.

70. Sevigny J, Chiao P, Bussiere T, Weinreb PH, Williams L, Maier M, et al. The antibody aducanumab reduces Abeta plaques in Alzheimer's disease. Nature. 2016;537(7618):50-6. 
71. Farlow MR, Andreasen N, Riviere ME, Vostiar I, Vitaliti A, Sovago J, et al. Long-term treatment with active Abeta immunotherapy with CAD106 in mild Alzheimer's disease. Alzheimer's research \& therapy. 2015;7(1):23.

72. Gilman S, Koller M, Black RS, Jenkins L, Griffith SG, Fox NC, et al. Clinical effects of Abeta immunization (AN1792) in patients with $\mathrm{AD}$ in an interrupted trial. Neurology. 2005;64(9):1553-62.

73. Lannfelt L, Blennow K, Zetterberg H, Batsman S, Ames D, Harrison J, et al. Safety, efficacy, and biomarker findings of PBT2 in targeting Abeta as a modifying therapy for Alzheimer's disease: a phase IIa, double-blind, randomised, placebo-controlled trial. Lancet Neurol. 2008;7(9):779-86.

74. Panza F, Lozupone M, Dibello V, Greco A, Daniele A, Seripa D, et al. Are antibodies directed against amyloid-beta (Abeta) oligomers the last call for the Abeta hypothesis of Alzheimer's disease? Immunotherapy. 2019;11(1):3-6.

75. Vandenberghe R, Riviere ME, Caputo A, Sovago J, Maguire RP, Farlow M, et al. Active Abeta immunotherapy CAD106 in Alzheimer's disease: A phase 2b study. Alzheimer's \& dementia (New York, N Y). 2017;3(1):10-22.

76. Winblad B, Andreasen N, Minthon L, Floesser A, Imbert G, Dumortier T, et al. Safety, tolerability, and antibody response of active Abeta immunotherapy with CAD106 in patients with Alzheimer's disease: randomised, double-blind, placebo-controlled, first-in-human study. Lancet Neurol. 2012;11(7):597-604.

77. Chiao P, Bedell BJ, Avants B, Zijdenbos AP, Grand'Maison M, O'Neill P, et al. Impact of Reference and Target Region Selection on Amyloid PET SUV Ratios in the Phase 1b PRIME Study of Aducanumab. Journal of nuclear medicine : official publication, Society of Nuclear Medicine. 2019;60(1):100-6.

78. Doggrell SA. Grasping at straws: the failure of solanezumab to modify mild Alzheimer's disease. Expert opinion on biological therapy. 2018;18(12):1189-92.

79. Honig LS, Vellas B, Woodward M, Boada M, Bullock R, Borrie M, et al. Trial of Solanezumab for Mild Dementia Due to Alzheimer's Disease. N Engl J Med. 2018;378(4):321-30.

80. Hsiao CC, Rombouts F, Gijsen HJM. New evolutions in the BACE1 inhibitor field from 2014 to 2018. Bioorganic \& medicinal chemistry letters. 2019.

81. Logovinsky V, Satlin A, Lai R, Swanson C, Kaplow J, Osswald G, et al. Safety and tolerability of BAN2401 - a clinical study in Alzheimer's disease with a protofibril selective A $\beta$ antibody. Alzheimer's research \& therapy. 2016;8(1):14.

82. Xia W. gamma-Secretase and its modulators: twenty years and beyond. Neuroscience letters. 2019.

83. Braak H, Braak E. Neuropathological stageing of Alzheimer-related changes. Acta Neuropathol. 1991;82(4):239-59. 
84. Braak H, Braak E. Frequency of stages of Alzheimer-related lesions in different age categories. Neurobiol Aging. 1997;18(4):351-7.

85. Taylor KI, Probst A. Anatomic localization of the transentorhinal region of the perirhinal cortex. Neurobiol Aging. 2008;29(10):1591-6.

86. Korte M. Neuronal function of Alzheimer's protein. Science. 2019;363(6423):123-4.

87. Olsson B, Lautner R, Andreasson U, Ohrfelt A, Portelius E, Bjerke M, et al. CSF and blood biomarkers for the diagnosis of Alzheimer's disease: a systematic review and meta-analysis. Lancet Neurol. 2016;15(7):673-84.

88. Coric V, van Dyck CH, Salloway S, Andreasen N, Brody M, Richter RW, et al. Safety and tolerability of the gamma-secretase inhibitor avagacestat in a phase 2 study of mild to moderate Alzheimer disease. Arch Neurol. 2012;69(11):1430-40.

89. Ortega F, Stott J, Visser SAG, Bendtsen C. Interplay between $\alpha-, \beta$-, and $\gamma$-Secretases Determines Biphasic Amyloid- $\beta$ Protein Level in the Presence of a $\gamma$-Secretase Inhibitor. The Journal of Biological Chemistry. 2013;288(2):785-92.

90. Tong G, Wang JS, Sverdlov O, Huang SP, Slemmon R, Croop R, et al. Multicenter, randomized, double-blind, placebo-controlled, single-ascending dose study of the oral gammasecretase inhibitor BMS-708163 (Avagacestat): tolerability profile, pharmacokinetic parameters, and pharmacodynamic markers. Clinical therapeutics. 2012;34(3):654-67.

91. Marathe S, Alberi L. Notch in memories: Points to remember. Hippocampus. 2015;25(12):1481-8.

92. Brai E, Marathe S, Astori S, Fredj NB, Perry E, Lamy C, et al. Notch1 Regulates Hippocampal Plasticity Through Interaction with the Reelin Pathway, Glutamatergic Transmission and CREB Signaling. Frontiers in cellular neuroscience. 2015;9:447.

93. Pierfelice T, Alberi L, Gaiano N. Notch in the vertebrate nervous system: an old dog with new tricks. Neuron. 2011;69(5):840-55.

94. Brai E, Alina Raio N, Alberi L. Notch1 hallmarks fibrillary depositions in sporadic Alzheimer's disease. Acta neuropathologica communications. 2016;4(1):64.

95. Cope TE, Rittman T, Borchert RJ, Jones PS, Vatansever D, Allinson K, et al. Tau burden and the functional connectome in Alzheimer's disease and progressive supranuclear palsy. Brain. 2018:awx347-awx.

96. Riley KP, Snowdon DA, Markesbery WR. Alzheimer's neurofibrillary pathology and the spectrum of cognitive function: findings from the Nun Study. Ann Neurol. 2002;51(5):567-77.

97. Bennett DA, Schneider JA, Bienias JL, Evans DA, Wilson RS. Mild cognitive impairment is related to Alzheimer disease pathology and cerebral infarctions. Neurology. 2005;64(5):834-41. 
98. Jadhav S, Avila J, Scholl M, Kovacs GG, Kovari E, Skrabana R, et al. A walk through tau therapeutic strategies. Acta neuropathologica communications. 2019;7(1):22.

99. Yanamandra K, Jiang H, Mahan TE, Maloney SE, Wozniak DF, Diamond MI, et al. Antitau antibody reduces insoluble tau and decreases brain atrophy. Ann Clin Transl Neurol. 2015;2(3):278-88.

100. Guo T, Noble W, Hanger DP. Roles of tau protein in health and disease. Acta Neuropathol. 2017;133(5):665-704.

101. Spires-Jones TL, Attems J, Thal DR. Interactions of pathological proteins in neurodegenerative diseases. Acta Neuropathol. 2017.

102. Ossenkoppele R, Mattsson N, Teunissen CE, Barkhof F, Pijnenburg Y, Scheltens P, et al. Cerebrospinal fluid biomarkers and cerebral atrophy in distinct clinical variants of probable Alzheimer's disease. Neurobiology of Aging. 2015;36(8):2340-7.

103. Degerman Gunnarsson M, Lannfelt L, Ingelsson M, Basun H, Kilander L. High tau levels in cerebrospinal fluid predict rapid decline and increased dementia mortality in Alzheimer's disease. Dement Geriatr Cogn Disord. 2014;37(3-4):196-206.

104. Kitamura S, Shimada H, Niwa F, Endo H, Shinotoh H, Takahata K, et al. Tau-induced focal neurotoxicity and network disruption related to apathy in Alzheimer's disease. J Neurol Neurosurg Psychiatry. 2018.

105. Braak H, Alafuzoff I, Arzberger T, Kretzschmar H, Del Tredici K. Staging of Alzheimer disease-associated neurofibrillary pathology using paraffin sections and immunocytochemistry. Acta Neuropathol. 2006;112(4):389-404.

106. Cho H, Choi JY, Hwang MS, Lee JH, Kim YJ, Lee HM, et al. Tau PET in Alzheimer disease and mild cognitive impairment. Neurology. 2016;87(4):375-83.

107. VAN HOESEN GW, Solodkin A. Cellular and systems neuroanatomical changes in Alzheimer's disease. Annals of the New York Academy of Sciences. 1994;747(1):12-35.

108. Van der Zee EA, Platt B, Riedel G. Acetylcholine: future research and perspectives. Behav Brain Res. 2011;221(2):583-6.

109. Ferreira-Vieira TH, Guimaraes IM, Silva FR, Ribeiro FM. Alzheimer's disease: Targeting the Cholinergic System. Curr Neuropharmacol. 2016;14(1):101-15.

110. Heneka MT, Carson MJ, Khoury JE, Landreth GE, Brosseron F, Feinstein DL, et al. Neuroinflammation in Alzheimer's disease. The Lancet Neurology. 2015;14(4):388-405.

111. Wang J, Tan L, Wang HF, Tan CC, Meng XF, Wang C, et al. Anti-inflammatory drugs and risk of Alzheimer's disease: an updated systematic review and meta-analysis. J Alzheimers Dis. 2015;44(2):385-96. 
112. Jaturapatporn D, Isaac MG, McCleery J, Tabet N. Aspirin, steroidal and non-steroidal antiinflammatory drugs for the treatment of Alzheimer's disease. Cochrane Database Syst Rev. 2012(2):CD006378.

113. Chou RC, Kane M, Ghimire S, Gautam S, Gui J. Treatment for Rheumatoid Arthritis and Risk of Alzheimer's Disease: A Nested Case-Control Analysis. CNS Drugs. 2016;30(11):1111-20.

114. Butchart J, Brook L, Hopkins V, Teeling J, Puntener U, Culliford D, et al. Etanercept in Alzheimer disease: A randomized, placebo-controlled, double-blind, phase 2 trial. Neurology. 2015;84(21):2161-8.

115. Pruss H, Lennox BR. Emerging psychiatric syndromes associated with antivoltage-gated potassium channel complex antibodies. J Neurol Neurosurg Psychiatry. 2016;87(11):1242-7.

116. Heneka MT, Golenbock DT, Latz E. Innate immunity in Alzheimer\&\#39;s disease. Nature Immunology. 2015;16:229.

117. Csernansky JG, Hamstra J, Wang L, McKeel D, Price JL, Gado M, et al. Correlations Between Antemortem Hippocampal Volume and Postmortem Neuropathology in AD Subjects. Alzheimer Disease \& Associated Disorders. 2004;18(4):190-5.

118. Whitwell JL, Josephs KA, Murray ME, Kantarci K, Przybelski SA, Weigand SD, et al. MRI correlates of neurofibrillary tangle pathology at autopsy. A voxel-based morphometry study. 2008;71(10):743-9.

119. Persson K, Eldholm RS, Barca ML, Cavallin L, Ferreira D, Knapskog A-B, et al. MRIassessed atrophy subtypes in Alzheimer's disease and the cognitive reserve hypothesis. PLOS ONE. 2017;12(10):e0186595.

120. Braak H, Braak E. Neuropathological stageing of Alzheimer-related changes. Acta neuropathologica. 1991;82(4):239-59.

121. Frisoni GB, Testa C, Zorzan A, Sabattoli F, Beltramello A, Soininen H, et al. Detection of grey matter loss in mild Alzheimer's disease with voxel based morphometry. Journal of Neurology, Neurosurgery \&amp; Psychiatry. 2002;73(6):657-64.

122. Karas GB, Scheltens P, Rombouts SARB, Visser PJ, van Schijndel RA, Fox NC, et al. Global and local gray matter loss in mild cognitive impairment and Alzheimer's disease. NeuroImage. 2004;23(2):708-16.

123. Rosenbloom MH, Alkalay A, Agarwal N, Baker SL, O'Neil JP, Janabi M, et al. Distinct clinical and metabolic deficits in PCA and AD are not related to amyloid distribution. Neurology. 2011;76(21):1789-96.

124. Shiino A, Watanabe T, Maeda K, Kotani E, Akiguchi I, Matsuda M. Four subgroups of Alzheimer's disease based on patterns of atrophy using VBM and a unique pattern for early onset disease. NeuroImage. 2006;33(1):17-26. 
125. Dickerson BC, McGinnis SM, Xia C, Price BH, Atri A, Murray ME, et al. Approach to atypical Alzheimer's disease and case studies of the major subtypes. CNS Spectrums. 2017;22(6):439-49.

126. Koedam ELGE, Lauffer V, van der Vlies AE, van der Flier WM, Scheltens P, Pijnenburg YAL. Early-Versus Late-Onset Alzheimer's Disease: More than Age Alone. Journal of Alzheimer's Disease. 2010;19:1401-8.

127. Murray ME, Graff-Radford NR, Ross OA, Petersen RC, Duara R, Dickson DW. Neuropathologically defined subtypes of Alzheimer's disease with distinct clinical characteristics: a retrospective study. The Lancet Neurology. 2011;10(9):785-96.

128. Whitwell JL, Dickson DW, Murray ME, Weigand SD, Tosakulwong N, Senjem ML, et al. Neuroimaging correlates of pathologically defined subtypes of Alzheimer's disease: a case-control study. The Lancet Neurology. 2012;11(10):868-77.

129. Byun MS, Kim SE, Park J, Yi D, Choe YM, Sohn BK, et al. Heterogeneity of Regional Brain Atrophy Patterns Associated with Distinct Progression Rates in Alzheimer's Disease. PLOS ONE. 2015;10(11):e0142756.

130. Ferreira D, Verhagen C, Hernández-Cabrera JA, Cavallin L, Guo C-J, Ekman U, et al. Distinct subtypes of Alzheimer's disease based on patterns of brain atrophy: longitudinal trajectories and clinical applications. Scientific Reports. 2017;7(1):46263.

131. Hwang J, Kim CM, Jeon S, Lee JM, Hong YJ, Roh JH, et al. Prediction of Alzheimer's disease pathophysiology based on cortical thickness patterns. Alzheimer's \& Dementia: Diagnosis, Assessment \& Disease Monitoring. 2016;2:58-67.

132. Harrison TM, La Joie R, Maass A, Baker SL, Swinnerton K, Fenton L, et al. Longitudinal tau accumulation and atrophy in aging and alzheimer disease. Annals of Neurology. 2019;85(2):229-40.

133. Pontecorvo MJ, Devous MD, Kennedy I, Navitsky M, Lu M, Galante N, et al. A multicentre longitudinal study of flortaucipir $(18 \mathrm{~F})$ in normal ageing, mild cognitive impairment and Alzheimer's disease dementia. Brain. 2019;142(6):1723-35.

134. Sintini I, Martin PR, Graff-Radford J, Senjem ML, Schwarz CG, Machulda MM, et al. Longitudinal tau-PET uptake and atrophy in atypical Alzheimer's disease. NeuroImage: Clinical. 2019;23:101823.

135. Brickman AM. Contemplating Alzheimer's disease and the contribution of white matter hyperintensities. Current neurology and neuroscience reports. 2013;13(12):415.

136. Lee S, Viqar F, Zimmerman ME, Narkhede A, Tosto G, Benzinger TLS, et al. White matter hyperintensities are a core feature of Alzheimer's disease: Evidence from the dominantly inherited Alzheimer network. Annals of Neurology. 2016;79(6):929-39. 
137. Graff-Radford J, Arenaza-Urquijo EM, Knopman DS, Schwarz CG, Brown RD, Jr, Rabinstein AA, et al. White matter hyperintensities: relationship to amyloid and tau burden. Brain. 2019;142(8):2483-91.

138. Phelps ME. Positron emission tomography provides molecular imaging of biological processes. Proceedings of the National Academy of Sciences. 2000;97(16):9226-33.

139. Schöll M, Lockhart Samuel N, Schonhaut Daniel R, O’Neil James P, Janabi M, Ossenkoppele R, et al. PET Imaging of Tau Deposition in the Aging Human Brain. Neuron. 2016;89(5):971-82.

140. Clark CM, Schneider JA, Bedell BJ, et al. Use of florbetapir-pet for imaging $\beta$-amyloid pathology. Jama. 2011;305(3):275-83.

141. Gordon BA, Blazey TM, Christensen J, Dincer A, Flores S, Keefe S, et al. Tau PET in autosomal dominant Alzheimer's disease: relationship with cognition, dementia and other biomarkers. Brain. 2019.

142. de Wilde A, van der Flier WM, Pelkmans W, Bouwman F, Verwer J, Groot C, et al. Association of Amyloid Positron Emission Tomography With Changes in Diagnosis and Patient Treatment in an Unselected Memory Clinic Cohort: The ABIDE Project. JAMA Neurol. 2018.

143. Murray ME, Lowe VJ, Graff-Radford NR, Liesinger AM, Cannon A, Przybelski SA, et al. Clinicopathologic and (11)C-Pittsburgh compound B implications of Thal amyloid phase across the Alzheimer's disease spectrum. Brain. 2015;138(5):1370-81.

144. Alongi P, Sardina DS, Coppola R, Scalisi S, Puglisi V, Arnone A, et al. 18F-Florbetaben PET/CT to Assess Alzheimer's Disease: A new Analysis Method for Regional Amyloid Quantification. Journal of neuroimaging : official journal of the American Society of Neuroimaging. 2019.

145. Jack CR, Wiste HJ, Weigand SD, Rocca WA, Knopman DS, Mielke MM, et al. Agespecific population frequencies of amyloidosis and neurodegeneration among cognitively normal people age 50-89 years: a cross-sectional study. Lancet Neurol. 2014;13(10):997-1005.

146. Jansen WJ, Ossenkoppele R, Knol DL, Tijms BM, Scheltens P, Verhey FR, et al. Prevalence of cerebral amyloid pathology in persons without dementia: a meta-analysis. Jama. 2015;313(19):1924-38.

147. Song Z, Insel PS, Buckley S, Yohannes S, Mezher A, Simonson A, et al. Brain amyloidbeta burden is associated with disruption of intrinsic functional connectivity within the medial temporal lobe in cognitively normal elderly. J Neurosci. 2015;35(7):3240-7.

148. Morbelli S, Piccardo A, Villavecchia G, Dessi B, Brugnolo A, Piccini A, et al. Mapping brain morphological and functional conversion patterns in amnestic MCI: a voxel-based MRI and FDG-PET study. Eur J Nucl Med Mol Imaging. 2010;37(1):36-45. 
149. Fukai M, Hirosawa T, Kikuchi M, Hino S, Kitamura T, Ouchi Y, et al. Different Patterns of Glucose Hypometabolism Underlie Functional Decline in Frontotemporal Dementia and Alzheimer's Disease: FDG-PET Study. Neuropsychiatry. 2018;8(2):441-7.

150. Langbaum JBS, Chen K, Caselli RJ, Lee W, Reschke C, Bandy D, et al. Hypometabolism in Alzheimer-Affected Brain Regions in Cognitively Healthy Latino Individuals Carrying the Apolipoprotein E $\varepsilon 4$ Allele. Archives of Neurology. 2010;67(4):462-8.

151. Ou Y-N, Xu W, Li J-Q, Guo Y, Cui M, Chen K-L, et al. FDG-PET as an independent biomarker for Alzheimer's biological diagnosis: a longitudinal study. Alzheimer's research \& therapy. 2019;11(1):57.

152. Meltzer CC, Zubieta JK, Brandt J, Tune LE, Mayberg HS, Frost JJ. Regional hypometabolism in Alzheimer's disease as measured by positron emission tomography after correction for effects of partial volume averaging. Neurology. 1996;47(2):454-61.

153. Adams JN, Lockhart SN, Li L, Jagust WJ. Relationships Between Tau and Glucose Metabolism Reflect Alzheimer's Disease Pathology in Cognitively Normal Older Adults. Cereb Cortex. 2018.

154. Smailagic N, Vacante M, Hyde C, Martin S, Ukoumunne O, Sachpekidis C. (1)(8)F-FDG PET for the early diagnosis of Alzheimer's disease dementia and other dementias in people with mild cognitive impairment (MCI). Cochrane Database Syst Rev. 2015;1:Cd010632.

155. Dennis EL, Thompson PM. Functional brain connectivity using fMRI in aging and Alzheimer's disease. Neuropsychol Rev. 2014;24(1):49-62.

156. Brier MR, Thomas JB, Ances BM. Network dysfunction in Alzheimer's disease: refining the disconnection hypothesis. Brain Connect. 2014;4(5):299-311.

157. Bernard C, Dilharreguy B, Helmer C, Chanraud S, Amieva H, Dartigues J-F, et al. PCC characteristics at rest in 10-year memory decliners. Neurobiology of aging. 2015;36(10):2812-20.

158. Chen Y, Yan H, Han Z, Bi Y, Chen H, Liu J, et al. Functional activity and connectivity differences of five resting-state networks in patients with Alzheimer's disease or mild cognitive impairment. Current Alzheimer research. 2016;13(3):234-42.

159. Çiftçi K. Minimum spanning tree reflects the alterations of the default mode network during Alzheimer's disease. Annals of biomedical engineering. 2011;39(5):1493-504.

160. Cope TE, Rittman T, Borchert RJ, Jones PS, Vatansever D, Allinson K, et al. Tau burden and the functional connectome in Alzheimer's disease and progressive supranuclear palsy. Brain. 2018;141(2):550-67.

161. Dai Z, Lin Q, Li T, Wang X, Yuan H, Yu X, et al. Disrupted structural and functional brain networks in Alzheimer's disease. Neurobiology of aging. 2019;75:71-82. 
162. Dai Z, Yan C, Li K, Wang Z, Wang J, Cao M, et al. Identifying and Mapping Connectivity Patterns of Brain Network Hubs in Alzheimer's Disease. Cerebral Cortex. 2014;25(10):3723-42.

163. Hahn K, Myers N, Prigarin S, Rodenacker K, Kurz A, Förstl H, et al. Selectively and progressively disrupted structural connectivity of functional brain networks in Alzheimer's disease - revealed by a novel framework to analyze edge distributions of networks detecting disruptions with strong statistical evidence. Neuroimage. 2013;81:96-109.

164. Perry A, Wen W, Lord A, Thalamuthu A, Roberts G, Mitchell PB, et al. The organisation of the elderly connectome. Neuroimage. 2015;114:414-26.

165. Greicius MD, Srivastava G, Reiss AL, Menon V. Default-mode network activity distinguishes Alzheimer's disease from healthy aging: Evidence from functional MRI. Proceedings of the National Academy of Sciences of the United States of America. 2004;101(13):4637-42.

166. Fornito A, Zalesky A, Breakspear M. The connectomics of brain disorders. Nature Reviews Neuroscience. 2015;16(3):159-72.

167. Bullmore E, Sporns O. Complex brain networks: Graph theoretical analysis of structural and functional systems. Nature Reviews Neuroscience. 2009;10(3):186-98.

168. Dennis EL, Thompson PM. Functional brain connectivity using fMRI in aging and Alzheimer's disease. Neuropsychology review. 2014;24(1):49-62.

169. Stam CJ. Modern network science of neurological disorders. Nature Reviews Neuroscience. 2014;15(10):683-95.

170. Tijms BM, Wink AM, de Haan W, van der Flier WM, Stam CJ, Scheltens P, et al. Alzheimer's disease: connecting findings from graph theoretical studies of brain networks. Neurobiology of Aging. 2013;34(8):2023-36.

171. van den Heuvel MP, de Lange SC, Zalesky A, Seguin C, Yeo BTT, Schmidt R. Proportional thresholding in resting-state fMRI functional connectivity networks and consequences for patientcontrol connectome studies: Issues and recommendations. Neuroimage. 2017;152:437-49.

172. van Wijk BCM, Stam CJ, Daffertshofer A. Comparing brain networks of different size and connectivity density using graph theory. PloS one. 2010;5(10):e13701-e.

173. Delbeuck X, Van der Linden M, Collette F. Alzheimer' Disease as a Disconnection Syndrome? Neuropsychology Review. 2003;13(2):79-92.

174. Solodkin A, Chen EE, Van Hoesen GW, Heimer L, Shereen A, Kruggel F, et al. In vivo parahippocampal white matter pathology as a biomarker of disease progression to Alzheimer's disease. Journal of Comparative Neurology. 2013;521(18):4300-17.

175. Hyman BT, Van Hoesen GW, Damasio AR, Barnes CL. Alzheimer's disease: cell-specific pathology isolates the hippocampal formation. Science. 1984;225(4667):1168-70. 
176. Stam CJ, De Haan W, Daffertshofer A, Jones BF, Manshanden I, van Cappellen van Walsum A-M, et al. Graph theoretical analysis of magnetoencephalographic functional connectivity in Alzheimer's disease. Brain. 2009;132(1):213-24.

177. Yan T, Wang W, Yang L, Chen K, Chen R, Han Y. Rich club disturbances of the human connectome from subjective cognitive decline to Alzheimer's disease. Theranostics. 2018;8(12):3237-.

178. Lo C-Y, Wang P-N, Chou K-H, Wang J, He Y, Lin C-P. Diffusion tensor tractography reveals abnormal topological organization in structural cortical networks in Alzheimer's disease. $\mathrm{J}$ Neurosci. 2010;30(50):16876-85.

179. Brier MR, Thomas JB, Fagan AM, Hassenstab J, Holtzman DM, Benzinger TL, et al. Functional connectivity and graph theory in preclinical Alzheimer's disease. Neurobiology of aging. 2014;35(4):757-68.

180. Buckner RL, Sepulcre J, Talukdar T, Krienen FM, Liu H, Hedden T, et al. Cortical Hubs Revealed by Intrinsic Functional Connectivity: Mapping, Assessment of Stability, and Relation to Alzheimer\&\#039;s Disease. The Journal of Neuroscience. 2009;29(6):1860 LP-73.

181. Chen G, Zhang H-Y, Xie C, Chen G, Zhang Z-J, Teng G-J, et al. Modular reorganization of brain resting state networks and its independent validation in Alzheimer's disease patients. Frontiers in human neuroscience. 2013;7:456-.

182. Xia M, Wang Z, Dai Z, Liang X, Song H, Shu N, et al. Differentially disrupted functional connectivity in posteromedial cortical subregions in Alzheimer's disease. Journal of Alzheimer's Disease. 2014;39(3):527-43.

183. Burggren A, Brown J. Imaging markers of structural and functional brain changes that precede cognitive symptoms in risk for Alzheimer's disease. Brain imaging and behavior. 2014;8(2):251-61.

184. Wang Z, Zhang M, Han Y, Song H, Guo R, Li K. Differentially disrupted functional connectivity of the subregions of the amygdala in Alzheimer's disease. Journal of X-ray Science and Technology. 2016;24(2):329-42.

185. Yao H, Liu Y, Zhou B, Zhang Z, An N, Wang P, et al. Decreased functional connectivity of the amygdala in Alzheimer's disease revealed by resting-state fMRI. European journal of radiology. 2013;82(9):1531-8.

186. Minati L, Chan D, Mastropasqua C, Serra L, Spanò B, Marra C, et al. Widespread alterations in functional brain network architecture in amnestic mild cognitive impairment. Journal of Alzheimer's Disease. 2014;40(1):213-20.

187. Pereira JB, Mijalkov M, Kakaei E, Mecocci P, Vellas B, Tsolaki M, et al. Disrupted network topology in patients with stable and progressive mild cognitive impairment and Alzheimer's disease. Cerebral Cortex. 2016;26(8):3476-93. 
188. Lo C-Y, Wang P-N, Chou K-H, Wang J, He Y, Lin C-P. Diffusion Tensor Tractography Reveals Abnormal Topological Organization in Structural Cortical Networks in Alzheimer\&\#039;s Disease. The Journal of Neuroscience. 2010;30(50):16876 LP-85.

189. Reijmer YD, Leemans A, Caeyenberghs K, Heringa SM, Koek HL, Biessels GJ. Disruption of cerebral networks and cognitive impairment in Alzheimer disease. Neurology. 2013;80(15):1370 LP-7.

190. Bullmore E, Sporns O. Complex brain networks: graph theoretical analysis of structural and functional systems. Nature Reviews Neuroscience. 2009;10(3):186-98.

191. Guillon J, Chavez M, Battiston F, Attal Y, La Corte V, Thiebaut de Schotten M, et al. Disrupted core-periphery structure of multimodal brain networks in Alzheimer's disease. Network Neuroscience. 2019;3(2):635-52.

192. Daianu M, Jahanshad N, Nir TM, Jack Jr CR, Weiner MW, Bernstein MA, et al. Rich club analysis in the Alzheimer's disease connectome reveals a relatively undisturbed structural core network. Human brain mapping. 2015;36(8):3087-103.

193. Zhao T, Sheng C, Bi Q, Niu W, Shu N, Han Y. Age-related differences in the topological efficiency of the brain structural connectome in amnestic mild cognitive impairment. Neurobiology of aging. 2017;59:144-55.

194. de Vos F, Koini M, Schouten TM, Seiler S, van der Grond J, Lechner A, et al. A comprehensive analysis of resting state fMRI measures to classify individual patients with Alzheimer's disease. Neuroimage. 2018;167:62-72.

195. Phillips DJ, McGlaughlin A, Ruth D, Jager LR, Soldan A, Initiative AsDN. Graph theoretic analysis of structural connectivity across the spectrum of Alzheimer's disease: the importance of graph creation methods. NeuroImage: Clinical. 2015;7:377-90.

196. Ye C, Mori S, Chan P, Ma T. Connectome-wide network analysis of white matter connectivity in Alzheimer's disease. NeuroImage: Clinical. 2019;22:101690-.

197. Gonneaud J, Baria AT, Binette AP, Gordon BA, Chhatwal JP, Cruchaga C, et al. Functional brain age prediction suggests accelerated aging in preclinical familial Alzheimer's disease, irrespective of fibrillar amyloid-beta pathology. bioRxiv. 2020.

198. Saito T, Matsuba Y, Mihira N, Takano J, Nilsson P, Itohara S, et al. Single App knock-in mouse models of Alzheimer's disease. Nature neuroscience. 2014;17(5):661-3.

199. Weintraub MK, Kranjac D, Eimerbrink MJ, Pearson SJ, Vinson BT, Patel J, et al. Peripheral administration of poly I:C leads to increased hippocampal amyloid-beta and cognitive deficits in a non-transgenic mouse. Behav Brain Res. 2014;266:183-7.

200. Sevush S, Peruyera G, Bertran A, Cisneros W. A three-factor model of cognition in Alzheimer disease. Cogn Behav Neurol. 2003;16(2):110-7. 
201. Koval I, Bône A, Louis M, Bottani S, Marcoux A, Samper-Gonzalez J, et al. Simulating Alzheimer's disease progression with personalised digital brain models. 2018.

202. Golriz Khatami S, Robinson C, Birkenbihl C, Domingo-Fernandez D, Hoyt CT, HofmannApitius M. Challenges of Integrative Disease Modeling in Alzheimer's Disease. Front Mol Biosci. 2019;6:158.

203. Bhagwat N, Viviano JD, Voineskos AN, Chakravarty MM, Initiative AsDN. Modeling and prediction of clinical symptom trajectories in Alzheimer's disease using longitudinal data. PLoS computational biology. 2018;14(9):e1006376.

204. Pellegrini E, Ballerini L, Hernandez M, Chappell FM, Gonzalez-Castro V, Anblagan D, et al. Machine learning of neuroimaging for assisted diagnosis of cognitive impairment and dementia: A systematic review. Alzheimers Dement (Amst). 2018;10:519-35.

205. Khanna S, Domingo-Fernández D, Iyappan A, Emon MA, Hofmann-Apitius M, Fröhlich H. Using multi-scale genetic, neuroimaging and clinical data for predicting alzheimer's disease and reconstruction of relevant biological mechanisms. Scientific reports. 2018;8(1):1-13.

206. George A, Howlett D. Computationally derived structural models of the $\beta$-amyloid found in Alzheimer's disease plaques and the interaction with possible aggregation inhibitors. Biopolymers: Original Research on Biomolecules. 1999;50(7):733-41.

207. Younesi E, Hofmann-Apitius M. From integrative disease modeling to predictive, preventive, personalized and participatory (P4) medicine. EPMA Journal. 2013;4(1):23.

208. Poil S-S, De Haan W, van der Flier WM, Mansvelder HD, Scheltens P, Linkenkaer-Hansen K. Integrative EEG biomarkers predict progression to Alzheimer's disease at the MCI stage. Frontiers in aging neuroscience. 2013;5:58.

209. Pellegrini E, Ballerini L, Hernandez M, Chappell FM, González-Castro V, Anblagan D, et al. Machine learning of neuroimaging for assisted diagnosis of cognitive impairment and dementia: A systematic review. Alzheimers Dement (Amst). 2018;10:519-35.

210. Domingo-Fernández D, Kodamullil AT, Iyappan A, Naz M, Emon MA, Raschka T, et al. Multimodal mechanistic signatures for neurodegenerative diseases (NeuroMMSig): a web server for mechanism enrichment. Bioinformatics. 2017;33(22):3679-81.

211. Markram H, Meier K, Lippert T, Grillner S, Frackowiak R, Dehaene S, et al. Introducing the Human Brain Project. Procedia Computer Science. 2011;7:39-42.

212. Jarrett JT, Berger EP, Lansbury PT. The carboxy terminus of the beta. amyloid protein is critical for the seeding of amyloid formation: Implications for the pathogenesis of Alzheimer's disease. Biochemistry. 1993;32(18):4693-7.

213. Lomakin A, Teplow DB, Kirschner DA, Benedek GB. Kinetic theory of fibrillogenesis of amyloid beta-protein. Proceedings of the National Academy of Sciences of the United States of America. 1997;94(15):7942-7. 
214. Pallitto MM, Murphy RM. A mathematical model of the kinetics of beta-amyloid fibril growth from the denatured state. Biophysical Journal. 2001;81(3):1805-22.

215. Anastasio TJ. Exploring the Contribution of Estrogen to Amyloid-Beta Regulation: A Novel Multifactorial Computational Modeling Approach. Frontiers in Pharmacology. 2013;4:16.

216. Anastasio TJ. Computational identification of potential multitarget treatments for ameliorating the adverse effects of amyloid- $\beta$ on synaptic plasticity. Frontiers in Pharmacology. 2014;5:85.

217. Kyrtsos CR, Baras JS. Studying the role of ApoE in Alzheimer's disease pathogenesis using a systems biology model. Journal of Bioinformatics and Computational Biology. 2013;11(05):1342003.

218. Proctor CJ, Boche D, Gray DA, Nicoll JAR. Investigating Interventions in Alzheimer's Disease with Computer Simulation Models. PLoS ONE. 2013;8(9):e73631.

219. Proctor CJ, Gray DA. GSK3 and p53 - is there a link in Alzheimer's disease? Molecular Neurodegeneration. 2010;5(1):7.

220. Tomski SJ, Murphy RM. Kinetics of aggregation of synthetic $\beta$-amyloid peptide. Archives of Biochemistry and Biophysics. 1992;294(2):630-8.

221. Lomakin A, Teplow DB, Kirschner DA, Benedek GB. Kinetic theory of fibrillogenesis of amyloid $\beta$-protein. Proceedings of the National Academy of Sciences. 1997;94(15):7942-7.

222. Pallitto MM, Murphy RM. A mathematical model of the kinetics of $\beta$-amyloid fibril growth from the denatured state. Biophysical journal. 2001;81(3):1805-22.

223. De Caluwé J, Dupont G. The progression towards Alzheimer's disease described as a bistable switch arising from the positive loop between amyloids and $\mathrm{Ca} 2+$. Journal of theoretical biology. 2013;331:12-8.

224. Proctor CJ, Gray DA. GSK3 and p53-is there a link in Alzheimer's disease? Molecular neurodegeneration. 2010;5(1):7.

225. Proctor CJ, Boche D, Gray DA, Nicoll JA. Investigating interventions in alzheimer's disease with computer simulation models. PloS one. 2013;8(9):e73631.

226. Madan S, Szostak J, Komandur Elayavilli R, Tsai RT-H, Ali M, Qian L, et al. The extraction of complex relationships and their conversion to biological expression language (BEL) overview of the BioCreative VI (2017) BEL track. Database : the journal of biological databases and curation. 2019;2019:baz084.

227. Bianchi D, De Michele P, Marchetti C, Tirozzi B, Cuomo S, Marie H, et al. Effects of increasing CREB-dependent transcription on the storage and recall processes in a hippocampal CA1 microcircuit. Hippocampus. 2014;24(2):165-77. 
228. Morse TM, Carnevale NT, Mutalik PG, Migliore M, Shepherd GM. Abnormal Excitability of Oblique Dendrites Implicated in Early Alzheimer's: A Computational Study. Frontiers in Neural Circuits. 2010;4:16.

229. Perez C, Ziburkus J, Ullah G. Analyzing and Modeling the Dysfunction of Inhibitory Neurons in Alzheimer's Disease. PLoS ONE. 2016;11(12):e0168800.

230. Romani A, Marchetti C, Bianchi D, Leinekugel X, Poirazi P, Migliore M, et al. Computational modeling of the effects of amyloid-beta on release probability at hippocampal synapses. Frontiers in Computational Neuroscience. 2013;7:1.

231. Abuhassan K, Coyle D, Maguire LP. Investigating the neural correlates of pathological cortical networks in Alzheimer's disease using heterogeneous neuronal models. IEEE transactions on bio-medical engineering. 2012;59(3):890-6.

232. Rowan MS, Neymotin SA, Lytton WW. Electrostimulation to reduce synaptic scaling driven progression of Alzheimer's disease. Frontiers in Computational Neuroscience. 2014;8:39.

233. Zou X, Coyle D, Wong-Lin K, Maguire L. Computational Study of Hippocampal-Septal Theta Rhythm Changes Due to Beta-Amyloid-Altered Ionic Channels. PLOS ONE. 2011;6(6):e21579.

234. Chen C. $\beta$-Amyloid increases dendritic $\mathrm{Ca} 2+$ influx by inhibiting the A-type $\mathrm{K}+$ current in hippocampal CA1 pyramidal neurons. Biochem Biophys Res Commun. 2005;338(4):1913-9.

235. Hindmarsh J, Rose R. A model of neuronal bursting using three coupled first order differential equations. Proceedings of the Royal Society of London B: Biological Sciences. 1984;221(1222):87-102.

236. Spiegler A, Knösche TR, Schwab K, Haueisen J, Atay FM. Modeling Brain Resonance Phenomena Using a Neural Mass Model. PLOS Computational Biology. 2011;7(12):e1002298.

237. Liley DT, Cadusch PJ, Dafilis MP. A spatially continuous mean field theory of electrocortical activity. Network: Computation in Neural Systems. 2002;13(1):67-113.

238. Sanz-Leon P, Knock SA, Spiegler A, Jirsa VK. Mathematical framework for large-scale brain network modeling in The Virtual Brain. NeuroImage. 2015;111:385-430.

239. Wilson HR, Cowan JD. Excitatory and Inhibitory Interactions in Localized Populations of Model Neurons. Biophysical Journal. 1972;12(1):1-24.

240. Wong K-F, Wang X-J. A Recurrent Network Mechanism of Time Integration in Perceptual Decisions. The Journal of Neuroscience. 2006;26(4):1314-28.

241. Zetterberg LH, Kristiansson L, Mossberg K. Performance of a model for a local neuron population. Biol Cybernetics. 1978;31(1):15-26. 
242. Stefanescu RA, Jirsa VK. A low dimensional description of globally coupled heterogeneous neural networks of excitatory and inhibitory neurons. PLoS Comput Biol. 2008;4(11):e1000219.

243. Jansen BH, Rit VG. Electroencephalogram and visual evoked potential generation in a mathematical model of coupled cortical columns. Biol Cybern. 1995;73(4):357-66.

244. de Haan W, Mott K, van Straaten EC, Scheltens P, Stam CJ. Activity dependent degeneration explains hub vulnerability in Alzheimer's disease. PLoS Comput Biol. 2012;8(8):e1002582.

245. de Haan W, van Straaten ECW, Gouw AA, Stam CJ. Altering neuronal excitability to preserve network connectivity in a computational model of Alzheimer's disease. PLOS Computational Biology. 2017;13(9):e1005707.

246. Pons AJ, Cantero JL, Atienza M, Garcia-Ojalvo J. Relating structural and functional anomalous connectivity in the aging brain via neural mass modeling. Neuroimage. 2010;52(3):84861 .

247. Jansen BH, Rit VG. Electroencephalogram and visual evoked potential generation in a mathematical model of coupled cortical columns. Biol Cybernetics. 1995;73(4):357-66.

248. Demirtaş M, Falcon C, Tucholka A, Gispert JD, Molinuevo JL, Deco G. A whole-brain computational modeling approach to explain the alterations in resting-state functional connectivity during progression of Alzheimer's disease. NeuroImage: Clinical. 2017;16:343-54.

249. Ritter P, Schirner M, McIntosh AR, Jirsa VK. The virtual brain integrates computational modeling and multimodal neuroimaging. Brain Connectivity. 2013;3(2):121-45.

250. Stefanovski L, Ghani A, McIntosh AR, Ritter P. Linking connectomics and dynamics in the human brain. Neuroforum. 2016;22(3):64-70.

251. Sanz Leon P, Knock SA, Woodman MM, Domide L, Mersmann J, McIntosh AR, et al. The Virtual Brain: a simulator of primate brain network dynamics. Frontiers in Neuroinformatics. $2013 ; 7(10)$.

252. Solodkin A, Zimmermann J, McIntosh AR, Stefanovski L, Ritter P. Neurological Biomarkers and Neuroinformatics: The Role of The Virtual Brain. In: Gerlai RT, editor. MolecularGenetic and Statistical Techniques for Behavioral and Neural Research. San Diego: Academic Press; 2018. p. 3-30.

253. Dipasquale O, Cercignani M. Network functional connectivity and whole-brain functional connectomics to investigate cognitive decline in neurodegenerative conditions. Funct Neurol. 2016;31(4):191-203.

254. Spiegler A, Jirsa V. Systematic approximations of neural fields through networks of neural masses in the virtual brain. NeuroImage. 2013;83:704-25. 
255. Deco G, Jirsa VK, Robinson PA, Breakspear M, Friston K. The Dynamic Brain: From Spiking Neurons to Neural Masses and Cortical Fields. PLOS Computational Biology. 2008;4(8):e1000092.

256. Wright JJ, Liley DTJ. Dynamics of the brain at global and microscopic scales: Neural networks and the EEG. Behavioral and Brain Sciences. 2010;19(2):285-95.

257. Sotero RC, Trujillo-Barreto NJ. Biophysical model for integrating neuronal activity, EEG, fMRI and metabolism. NeuroImage. 2008;39(1):290-309.

258. Bojak I, Oostendorp TF, Reid AT, Kötter R. Connecting Mean Field Models of Neural Activity to EEG and fMRI Data. Brain Topography. 2010;23(2):139-49.

259. Kunze T, Hunold A, Haueisen J, Jirsa V, Spiegler A. Transcranial direct current stimulation changes resting state functional connectivity: A large-scale brain network modeling study. NeuroImage. 2016;140:174-87.

260. Honey CJ, Kotter R, Breakspear M, Sporns O. Network structure of cerebral cortex shapes functional connectivity on multiple time scales. Proceedings of the National Academy of Sciences of the United States of America. 2007;104(24):10240-5.

261. Jirsa VK, Sporns O, Breakspear M, Deco G, McIntosh AR. Towards the virtual brain: network modeling of the intact and the damaged brain. Arch Ital Biol. 2010;148(3):189-205.

262. Ghosh A, Rho Y, McIntosh AR, Kotter R, Jirsa VK. Noise during rest enables the exploration of the brain's dynamic repertoire. PLoS Comput Biol. 2008;4(10):e1000196.

263. Jirsa VK, Proix T, Perdikis D, Woodman MM, Wang H, Gonzalez-Martinez J, et al. The Virtual Epileptic Patient: Individualized whole-brain models of epilepsy spread. Neuroimage. 2017;145(Pt B):377-88.

264. Roy D, Sigala R, Breakspear M, McIntosh AR, Jirsa VK, Deco G, et al. Using the virtual brain to reveal the role of oscillations and plasticity in shaping brain's dynamical landscape. Brain Connect. 2014;4(10):791-811.

265. Melozzi F, Woodman MM, Jirsa VK, Bernard C. The Virtual Mouse Brain: A Computational Neuroinformatics Platform to Study Whole Mouse Brain Dynamics. eNeuro. 2017;4(3):ENEURO.0111-17.2017.

266. Stefanovski L, Triebkorn P, Spiegler A, Diaz-Cortes M-A, Solodkin A, Jirsa V, et al. Linking Molecular Pathways and Large-Scale Computational Modeling to Assess Candidate Disease Mechanisms and Pharmacodynamics in Alzheimer's Disease. Frontiers in Computational Neuroscience. 2019;13(54).

267. Zimmermann J, Perry A, Breakspear M, Schirner M, Sachdev P, Wen W, et al. Differentiation of Alzheimer's disease based on local and global parameters in personalized Virtual Brain models. NeuroImage: Clinical. 2018;19:240-51. 
268. Proix T, Bartolomei F, Guye M, Jirsa VK. Individual brain structure and modelling predict seizure propagation. Brain. 2017;140(3):641-54.

269. Falcon MI, Riley JD, Jirsa V, McIntosh AR, Elinor Chen E, Solodkin A. Functional Mechanisms of Recovery after Chronic Stroke: Modeling with the Virtual Brain. eNeuro. 2016;3(2):ENEURO.0158-15.2016.

270. Falcon MI, Riley JD, Jirsa V, McIntosh AR, Shereen AD, Chen EE, et al. The Virtual Brain: Modeling Biological Correlates of Recovery after Chronic Stroke. Front Neurol. 2015;6:228.

271. Aerts H, Schirner M, Jeurissen B, Van Roost D, Achten E, Ritter P, et al. Modeling Brain Dynamics in Brain Tumor Patients Using the Virtual Brain. eNeuro. 2018;5(3).

272. Hofmann-Apitius M, Alarcon-Riquelme ME, Chamberlain C, McHale D. Towards the taxonomy of human disease. Nature Reviews Drug Discovery. 2015;14(2):75-6.

273. Iyappan A, Gundel M, Shahid M, Wang J, Li H, Mevissen HT, et al. Towards a Pathway Inventory of the Human Brain for Modeling Disease Mechanisms Underlying Neurodegeneration. Journal of Alzheimer's Disease. 2016;52(4):1343-60.

274. Iturria-Medina Y, Carbonell FM, Evans AC. Multimodal imaging-based therapeutic fingerprints for optimizing personalized interventions: Application to neurodegeneration. Neuroimage. 2018.

275. Sweeney MD, Sagare AP, Zlokovic BV. Blood-brain barrier breakdown in Alzheimer disease and other neurodegenerative disorders. Nat Rev Neurol. 2018;14(3):133-50.

276. Schneider LS, Mangialasche F, Andreasen N, Feldman H, Giacobini E, Jones R, et al. Clinical trials and late-stage drug development for Alzheimer's disease: an appraisal from 1984 to 2014. Journal of Internal Medicine. 2014;275(3):251-83.

277. Oertel WH. Recent advances in treating Parkinson's disease. F1000Research. 2017;6:260.

278. Young JJ, Lavakumar M, Tampi D, Balachandran S, Tampi RR. Frontotemporal dementia: latest evidence and clinical implications. Therapeutic advances in psychopharmacology. 2018;8(1):33-48.

279. Vellas B, Sol O, Snyder PJ, Ousset PJ, Haddad R, Maurin M, et al. EHT0202 in Alzheimer's disease: a 3-month, randomized, placebo-controlled, double-blind study. Current Alzheimer research. 2011;8(2):203-12.

280. Geldmacher DS, Fritsch T, McClendon MJ, Landreth G. A randomized pilot clinical trial of the safety of pioglitazone in treatment of patients with Alzheimer disease. Arch Neurol. 2011;68(1):45-50.

281. Cebers G, Alexander RC, Haeberlein SB, Han D, Goldwater R, Ereshefsky L, et al. AZD3293: Pharmacokinetic and Pharmacodynamic Effects in Healthy Subjects and Patients with Alzheimer's Disease. J Alzheimers Dis. 2017;55(3):1039-53. 
282. Galimberti D, Scarpini E. Pioglitazone for the treatment of Alzheimer's disease. Expert opinion on investigational drugs. 2017;26(1):97-101.

283. Heneka MT, Fink A, Doblhammer G. Effect of pioglitazone medication on the incidence of dementia. Ann Neurol. 2015;78(2):284-94.

284. Read S, Wu P, Biscow M. Sustained 4-year cognitive and functional response in early Alzheimer's disease with pioglitazone. Journal of the American Geriatrics Society. 2014;62(3):5846.

285. Green RC, Schneider LS, Amato DA, Beelen AP, Wilcock G, Swabb EA, et al. Effect of tarenflurbil on cognitive decline and activities of daily living in patients with mild Alzheimer disease: a randomized controlled trial. Jama. 2009;302(23):2557-64.

286. Morimoto B. Drug Development for Neurodegenerative Diseases--Second Annual marcus evans Conference. Advances in drug development for NDD and expediting discovery through novel compounds and sound clinical trials. IDrugs : the investigational drugs journal. 2010;13(7):440-3.

287. Faux NG, Ritchie CW, Gunn A, Rembach A, Tsatsanis A, Bedo J, et al. PBT2 rapidly improves cognition in Alzheimer's Disease: additional phase II analyses. J Alzheimers Dis. 2010;20(2):509-16.

288. Siemers ER, Sundell KL, Carlson C, Case M, Sethuraman G, Liu-Seifert H, et al. Phase 3 solanezumab trials: Secondary outcomes in mild Alzheimer's disease patients. Alzheimers Dement. 2016;12(2):110-20.

289. Mo JJ, Li Jy, Yang Z, Liu Z, Feng JS. Efficacy and safety of anti-amyloid- $\beta$ immunotherapy for Alzheimer's disease: a systematic review and network meta-analysis. Annals of Clinical and Translational Neurology. 2017;4(12):931-42.

290. Forlenza OV, Diniz BS, Radanovic M, Santos FS, Talib LL, Gattaz WF. Disease-modifying properties of long-term lithium treatment for amnestic mild cognitive impairment: randomised controlled trial. The British journal of psychiatry : the journal of mental science. 2011;198(5):3516.

291. Hampel H, Ewers M, Burger K, Annas P, Mortberg A, Bogstedt A, et al. Lithium trial in Alzheimer's disease: a randomized, single-blind, placebo-controlled, multicenter 10-week study. The Journal of clinical psychiatry. 2009;70(6):922-31.

292. Morimoto BH, Schmechel D, Hirman J, Blackwell A, Keith J, Gold M. A double-blind, placebo-controlled, ascending-dose, randomized study to evaluate the safety, tolerability and effects on cognition of AL-108 after 12 weeks of intranasal administration in subjects with mild cognitive impairment. Dement Geriatr Cogn Disord. 2013;35(5-6):325-36.

293. Freund-Levi Y, Eriksdotter-Jonhagen M, Cederholm T, Basun H, Faxen-Irving G, Garlind A, et al. Omega-3 fatty acid treatment in 174 patients with mild to moderate Alzheimer disease: OmegAD study: a randomized double-blind trial. Arch Neurol. 2006;63(10):1402-8. 
294. Freund-Levi Y, Hjorth E, Lindberg C, Cederholm T, Faxen-Irving G, Vedin I, et al. Effects of omega-3 fatty acids on inflammatory markers in cerebrospinal fluid and plasma in Alzheimer's disease: the OmegAD study. Dement Geriatr Cogn Disord. 2009;27(5):481-90.

295. Quinn JF, Raman R, Thomas RG, Yurko-Mauro K, Nelson EB, Van Dyck C, et al. Docosahexaenoic acid supplementation and cognitive decline in Alzheimer disease: a randomized trial. Jama. 2010;304(17):1903-11.

296. Arai H, Takahashi T. A combination therapy of donepezil and cilostazol for patients with moderate Alzheimer disease: pilot follow-up study. Am J Geriatr Psychiatry. 2009;17(4):353-4.

297. Folch J, Petrov D, Ettcheto M, Pedros I, Abad S, Beas-Zarate C, et al. Masitinib for the treatment of mild to moderate Alzheimer's disease. Expert review of neurotherapeutics. 2015;15(6):587-96.

298. Sano M, Bell KL, Galasko D, Galvin JE, Thomas RG, van Dyck CH, et al. A randomized, double-blind, placebo-controlled trial of simvastatin to treat Alzheimer disease. Neurology. 2011;77(6):556-63.

299. Li G, Mayer CL, Morelli D, Millard SP, Raskind WH, Petrie EC, et al. Effect of simvastatin on CSF Alzheimer disease biomarkers in cognitively normal adults. Neurology. 2017;89(12):12515 .

300. Craft S, Baker LD, Montine TJ, Minoshima S, Watson GS, Claxton A, et al. Intranasal insulin therapy for Alzheimer disease and amnestic mild cognitive impairment: a pilot clinical trial. Arch Neurol. 2012;69(1):29-38.

301. Wahlberg LU, Lind G, Almqvist PM, Kusk P, Tornoe J, Juliusson B, et al. Targeted delivery of nerve growth factor via encapsulated cell biodelivery in Alzheimer disease: a technology platform for restorative neurosurgery. J Neurosurg. 2012;117(2):340-7.

302. Eyjolfsdottir H, Eriksdotter M, Linderoth B, Lind G, Juliusson B, Kusk P, et al. Targeted delivery of nerve growth factor to the cholinergic basal forebrain of Alzheimer's disease patients: application of a second-generation encapsulated cell biodelivery device. Alzheimer's research \& therapy. 2016;8(1):30.

303. Tuszynski MH, Yang JH, Barba D, U HS, Bakay RA, Pay MM, et al. Nerve Growth Factor Gene Therapy: Activation of Neuronal Responses in Alzheimer Disease. JAMA Neurol. 2015;72(10):1139-47.

304. Hardenacke K, Shubina E, Buhrle CP, Zapf A, Lenartz D, Klosterkotter J, et al. Deep brain stimulation as a tool for improving cognitive functioning in Alzheimer's dementia: a systematic review. Frontiers in psychiatry. 2013;4:159.

305. Nardone R, Holler Y, Tezzon F, Christova M, Schwenker K, Golaszewski S, et al. Neurostimulation in Alzheimer's disease: from basic research to clinical applications. Neurological sciences : official journal of the Italian Neurological Society and of the Italian Society of Clinical Neurophysiology. 2015;36(5):689-700. 
306. Salma A, Vasilakis M, Tracy PT. Deep brain stimulation for cognitive disorders: insights into targeting nucleus basalis of meynert in Alzheimer dementia. World Neurosurg. 2014;81(1):e45 .

307. Bittlinger M, Muller S. Opening the debate on deep brain stimulation for Alzheimer disease - a critical evaluation of rationale, shortcomings, and ethical justification. BMC medical ethics. 2018;19(1):41.

308. Lv Q, Du A, Wei W, Li Y, Liu G, Wang XP. Deep Brain Stimulation: A Potential Treatment for Dementia in Alzheimer's Disease (AD) and Parkinson's Disease Dementia (PDD). Frontiers in neuroscience. 2018;12:360.

309. Floel A. tDCS-enhanced motor and cognitive function in neurological diseases. Neuroimage. 2014;85 Pt 3:934-47.

310. Freitas C, Mondragon-Llorca H, Pascual-Leone A. Noninvasive brain stimulation in Alzheimer's disease: systematic review and perspectives for the future. Exp Gerontol. 2011;46(8):611-27.

311. Lefaucheur JP, Antal A, Ayache SS, Benninger DH, Brunelin J, Cogiamanian F, et al. Evidence-based guidelines on the therapeutic use of transcranial direct current stimulation (tDCS). Clin Neurophysiol. 2017;128(1):56-92.

312. Nardone R, Tezzon F, Holler Y, Golaszewski S, Trinka E, Brigo F. Transcranial magnetic stimulation (TMS)/repetitive TMS in mild cognitive impairment and Alzheimer's disease. Acta Neurol Scand. 2014;129(6):351-66.

313. Day GS. Reversible Dementias. Continuum (Minneap Minn). 2019;25(1):234-53.

314. de Haan W, Pijnenburg YAL, Strijers RLM, van der Made Y, van der Flier WM, Scheltens $\mathrm{P}$, et al. Functional neural network analysis in frontotemporal dementia and Alzheimer's disease using EEG and graph theory. BMC Neuroscience. 2009;10(1):101.

315. Stam CJ, Jones BF, Nolte G, Breakspear M, Scheltens P. Small-world networks and functional connectivity in Alzheimer's disease. Cereb Cortex. 2007;17(1):92-9.

316. Stam CJ, de Haan W, Daffertshofer A, Jones BF, Manshanden I, van Cappellen van Walsum $\mathrm{AM}$, et al. Graph theoretical analysis of magnetoencephalographic functional connectivity in Alzheimer's disease. Brain. 2009;132(Pt 1):213-24.

317. Sanz-Arigita EJ, Schoonheim MM, Damoiseaux JS, Rombouts SA, Maris E, Barkhof F, et al. Loss of 'small-world' networks in Alzheimer's disease: graph analysis of FMRI resting-state functional connectivity. PLoS One. 2010;5(11):e13788.

318. Zhao X, Liu Y, Wang X, Liu B, Xi Q, Guo Q, et al. Disrupted Small-World Brain Networks in Moderate Alzheimer's Disease: A Resting-State fMRI Study. PLOS ONE. 2012;7(3):e33540. 
319. Supekar K, Menon V, Rubin D, Musen M, Greicius MD. Network Analysis of Intrinsic Functional Brain Connectivity in Alzheimer's Disease. PLoS Computational Biology. 2008;4(6):e1000100.

320. He Y, Chen Z, Evans A. Structural Insights into Aberrant Topological Patterns of LargeScale Cortical Networks in Alzheimer's Disease. The Journal of Neuroscience. 2008;28(18):475666.

321. Yao Z, Zhang Y, Lin L, Zhou Y, Xu C, Jiang T, et al. Abnormal Cortical Networks in Mild Cognitive Impairment and Alzheimer's Disease. PLOS Computational Biology. 2010;6(11):e1001006.

322. Bosscher L, Scheltens P. II. 4.7 MRI of the Medial Temporal Lobe for the Diagnosis of Alzheimer's Disease. Evidence Based Dementia Practice. 2002:154.

323. van der Flier WM, van Straaten ECW, Barkhof F, Ferro JM, Pantoni L, Basile AM, et al. Medial temporal lobe atrophy and white matter hyperintensities are associated with mild cognitive deficits in non-disabled elderly people: the LADIS study. Journal of Neurology, Neurosurgery \&amp; Psychiatry. 2005;76(11):1497-500.

324. Shi F, Liu B, Zhou Y, Yu C, Jiang T. Hippocampal volume and asymmetry in mild cognitive impairment and Alzheimer's disease: Meta-analyses of MRI studies. Hippocampus. 2009;19(11):1055-64.

325. Blanc F, Colloby SJ, Philippi N, de Pétigny X, Jung B, Demuynck C, et al. Cortical Thickness in Dementia with Lewy Bodies and Alzheimer's Disease: A Comparison of Prodromal and Dementia Stages. PLOS ONE. 2015;10(6):e0127396.

326. Bobinski M, de Leon MJ, Convit A, Santi SD, Wegiel J, Tarshish CY, et al. MRI of entorhinal cortex in mild Alzheimer's disease. The Lancet. 1999;353(9146):38-40.

327. Dickerson BC, Goncharova I, Sullivan MP, Forchetti C, Wilson RS, Bennett DA, et al. MRI-derived entorhinal and hippocampal atrophy in incipient and very mild Alzheimer's

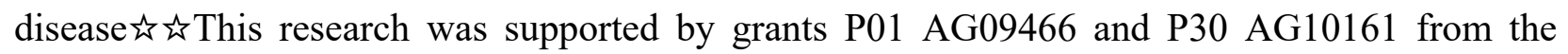
National Institute on Aging, National Institutes of Health. Neurobiology of Aging. 2001;22(5):74754 .

328. Teipel SJ, Pruessner JC, Faltraco F, Born C, Rocha-Unold M, Evans A, et al. Comprehensive dissection of the medial temporal lobe in AD: measurement of hippocampus, amygdala, entorhinal, perirhinal and parahippocampal cortices using MRI. Journal of Neurology. 2006;253(6):794-800.

329. Velayudhan L, Proitsi P, Westman E, Muehlboeck JS, Mecocci P, Vellas B, et al. Entorhinal Cortex Thickness Predicts Cognitive Decline in Alzheimer's Disease. Journal of Alzheimer's Disease. 2013;33:755-66.

330. Barnes J, Whitwell JL, Frost C, Josephs KA, Rossor M, Fox NC. Measurements of the Amygdala and Hippocampus in Pathologically Confirmed Alzheimer Disease and Frontotemporal Lobar Degeneration. Archives of Neurology. 2006;63(10):1434-9. 
331. Whitwell JL, Sampson EL, Watt HC, Harvey RJ, Rossor MN, Fox NC. A Volumetric Magnetic Resonance Imaging Study of the Amygdala in Frontotemporal Lobar Degeneration and Alzheimer's Disease. Dementia and Geriatric Cognitive Disorders. 2005;20(4):238-44.

332. Callen DJA, Black SE, Gao F, Caldwell CB, Szalai JP. Beyond the hippocampus. MRI volumetry confirms widespread limbic atrophy in AD. 2001;57(9):1669-74.

333. Yi H-A, Möller C, Dieleman N, Bouwman FH, Barkhof F, Scheltens P, et al. Relation between subcortical grey matter atrophy and conversion from mild cognitive impairment to Alzheimer's disease. Journal of Neurology, Neurosurgery \&amp; Psychiatry. 2016;87(4):425-32.

334. Madsen SK, Ho AJ, Hua X, Saharan PS, Toga AW, Jack CR, et al. 3D maps localize caudate nucleus atrophy in 400 Alzheimer's disease, mild cognitive impairment, and healthy elderly subjects. Neurobiology of Aging. 2010;31(8):1312-25.

335. Rombouts SARB, Barkhof F, Witter MP, Scheltens P. Unbiased whole-brain analysis of gray matter loss in Alzheimer's disease. Neuroscience letters. 2000;285(3):231-3.

336. Liu Y, Paajanen T, Zhang Y, Westman E, Wahlund L-O, Simmons A, et al. Analysis of regional MRI volumes and thicknesses as predictors of conversion from mild cognitive impairment to Alzheimer's disease. Neurobiology of Aging. 2010;31(8):1375-85.

337. Chang YT, Huang CW, Chang YH, Chen NC, Lin KJ, Yan TC, et al. Amyloid burden in the hippocampus and default mode network: relationships with gray matter volume and cognitive performance in mild stage Alzheimer disease. Medicine (Baltimore). 2015;94(16):e763. 